\title{
Phase I Chemical Speciation Modeling of Sream Mixing in the LAW/HLW Envelope A Treatment
}

by

D. I. Kaplan

Westinghouse Savannah River Company

Savannah River Site

Aiken, South Carolina 29808

D. McCabe

S. M. Serkiz

DOE Contract No. DE-AC09-96SR18500

This paper was prepared in connection with work done under the above contract number with the U.S.

Department of Energy. By acceptance of this paper, the publisher and/or recipient acknowledges the U. S.

Government's right to retain a nonexclusive, royalty-free license in and to any copyright covering this paper, along with the right to reproduce and to authorize others to reproduce all or part of the copyrighted paper. 


\section{DISCLAIMER}

This report was prepared as an account of work sponsored by an agency of the United States Government. Neither the United States Government nor any agency thereof, nor any of their employees, makes any warranty, express or implied, or assumes any legal liability or responsibility for the accuracy, completeness, or usefulness of any information, apparatus, product or process disclosed, or represents that its use would not infringe privately owned rights. Reference herein to any specific commercial product, process or service by trade name, trademark, manufacturer, or otherwise does not necessarily constitute or imply its endorsement, recommendation, or favoring by the United States Government or any agency thereof. The views and opinions of authors expressed herein do not necessarily state or reflect those of the United States Government or any agency thereof.

This report has been reproduced directly from the best available copy.

Available for sale to the public, in paper, from: U.S. Department of Commerce, National Technical Information Service, 5285 Port Royal Road, Springfield, VA 22161

phone: (800) 553-6847

fax: (703) 605-6900

email: orders@ntis.fedworld.gov

online ordering: http://www.ntis.gov/ordering.htm

Available electronically at http://www.doe.gov/bridge

Available for a processing fee to U.S. Department of Energy and its contractors, in paper, from: U.S. Department of Energy, Office of Scientific and Technical Information, P.O. Box 62, Oak Ridge, TN 37831-0062

phone: (865)576-8401

fax: (865)576-5728

email: reports@adonis.osti.gov 


\section{DISCLAIMER}

Portions of this document may be illegible in electronic image products. Images are produced from the best available original document. 
Phase I Chemical Speciation Modeling of Stream Mixing in the LAW/HLW Envelope A Treatment Process

September 21, 1999

\author{
Daniel Kaplan \\ Daniel McCabe \\ Steven Serkiz
}

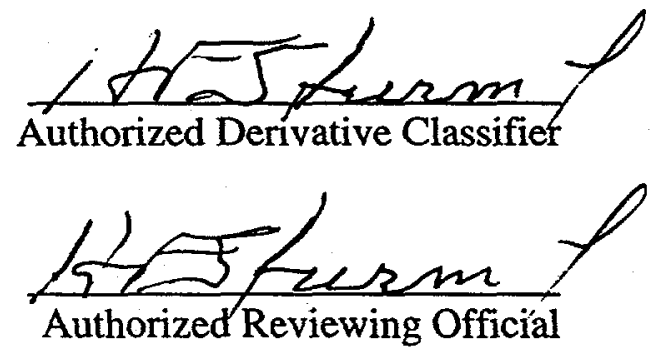

\title{
DISCLAIMER NOTICE
}

This report was prepared by Westinghouse Savannah River Company, Inc. (WSRC) on behalf of the U.S. Department of Energy (DOE), as an account of work sponsored by BNFL, Inc. Neither WSRC, DOE, the U.S. Government, or any person acting on their behalf makes any warranty, express or implied, or assumes any legal liability or responsibility for the accuracy, completeness, or usefulness of any information, apparatus, product, or process disclosed, or represents that its use would not infringe privately owned rights. Reference herein to any specific commercial product, process, or service by trade name, trademark, manufacturer, or otherwise, does not necessarily constitute or imply its endorsement, recommendation, or favoring by WSRC, DOE, or the U.S. Government. The views and opinions of authors expressed herein do not necessarily state or reflect those of WSRC, DOE, or the U.S. Government. 


\section{SUMMARY}

A series of chemical equilibrium calculations were conducted to provide a first approximation of the influence of mixing various waste streams on the formation of solids. Solids are undesirable in the waste stream because they can clog filters, reduce the efficiency of ion exchange resins, and increase the amount of non-radioactive material ultimately transferred to the high activity glassification process. Two general approaches were used in these calculations. First, streams previously identified from flowsheet calculations (Colebrook and Coleman 1998a, 1998b) were combined at various ratios and the concentrations of the aqueous and solid constituents in the resulting mixtures were calculated. Secondly, Envelope A was titrated with acids or salts and then the concentrations of the aqueous and solid constituents were calculated. Where possible, attempts were made to compare simulated results with reported laboratory results. No attempt was made during this study to elucidate radionuclide chemical behavior, including the propensity of radionuclides to be removed by the various treatment units or (co)precipitation. Additionally, no attempt was made to evaluate the influence of redox status on the formation of solids. Although these are important processes, these mixing parameters will be addressed once laboratory experiments have been completed to provide needed conceptual and numerical modeling input. The software program used, Environmental Simulation Program by OLI, Inc., performs the calculations using thermodynamic equilibrium equations.

Three mixing issues were evaluated: acidification, dilution, and tank heel mixing. The acidification issue is concerned with the formation of precipitates as a result of mixing an acidic stream with the main process stream. Examples of acidic waste streams include the cleaning solution from the HLW or LAW ultrafiltration systems and the HLW and LAW melter off-gas condensate streams. The dilution issue is concerned with the formation of precipitates by mixing a dilute waste stream with the main process stream, thereby lowering the solution $\mathrm{pH}$. Examples of dilute waste streams include the water wash streams of the HLW (Envelope D) and LAW entrained solids. The heel issue is concerned with the formation of precipitates by mixing Envelope A or B feed streams with the heel of Envelope $\mathrm{C}$ feed stream remaining in a storage vessel.

This is the first phase of our modeling effort. The intent of this work was to provide a first approximation of the effect of stream mixing and waste stream composition on precipitation. The other intent is to provide guidance for designing subsequent laboratory studies. This work will provide the basis for more refined modeling that will include data generated from laboratory studies. The emphasis of this study was to identify the conditions for which precipitation of solids in Envelope A was predicted.

Dilution of Envelope A (Tank AW-101) with a simulated LAW solids leachate stream resulted in a significant decline in total solids formed. This is qualitatively consistent with observations made by WSRC personnel. Upon dilution, the mixture became increasingly acidic, but the acidity never dropped below the point where substantial amount of solids were formed. There was a marked increase in the amount of solids formed upon the acidification of Envelope A. Envelope A was highly buffered at elevated pH levels ( $\mathrm{pH}$ 
16.5 to 15.5 ), thereby providing added insurance against the precipitation of solids as a result of variations in solution chemistry during the treatment of the waste for glassification. Mixing of simulated acidic waste streams into Envelope A did not promote the formation of solids owing to the concomitant dilution of salt with increased acidity in the system. Upon diluting and/or acidifying Envelope A, the composition of solids formed tended to change from sodium to aluminum and iron solids. It is not known what the implications of this change will be on the waste pretreatment process.

Effects of mixing Envelopes A (Tank AW-101) and C (Tank AN-107) were not addressed satisfactorily in these simulations due to software and data limitations. This mixing scenario will be addressed in future modeling efforts. However, the simulations conducted suggested that mixing the supernatants of Envelope $C$ into Envelope A did not result in an increase in the total solids in the system. Oxalate formed more precipitates than acetate, formate, or glycolate, and the presence of EDTA (a chelating agent) did not reduce greatly the amount of solids formed. The concentration of organic compounds had a profound effect on the total solid concentrations.

These simulations provided important guidance for defining future laboratory studies and for identifying data needs for more in-depth evaluations of stream mixing issues. The laboratory studies identified in this report will provide important conceptual constructs (e.g., which solid-phase precipitates to include in model; whether to invoke redox chemistry, Tc-organic complexation, or radionuclide precipitation/coprecipitation; whether to include $\mathrm{NaNO}_{3}$ solids) and numerical constants (e.g., solubility values) for more in-depth and technically defensible modeling of the various mixing scenarios. 


\section{CONTENTS}

1. SUMMARY …

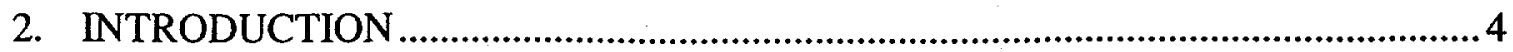

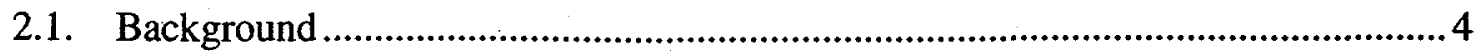

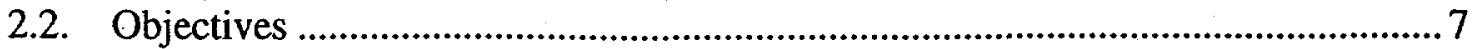

2.3. Scope

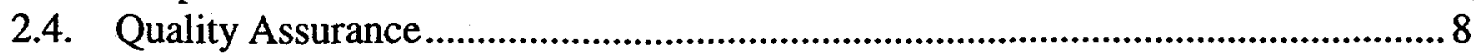

3. EXPERIMENTAL

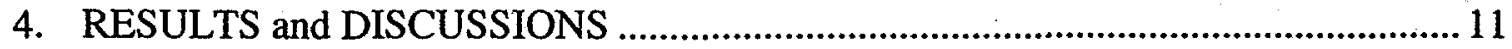

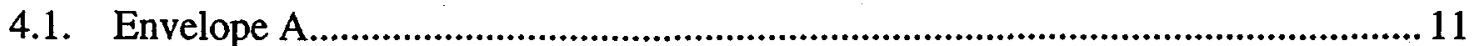

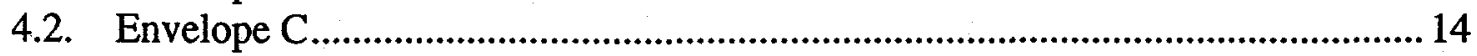

4.3. Organic Compounds in Envelope A ……....................................................... 17

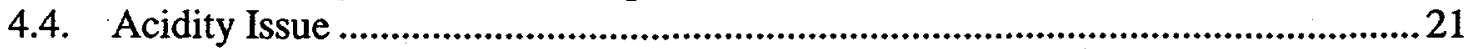

4.4.1. Titration of Envelope A with Nitric Acid ....................................................2

4.4.2. Mixing of an Off-Gas Condensate Stream with Envelope A.........................25

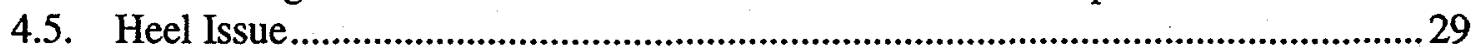

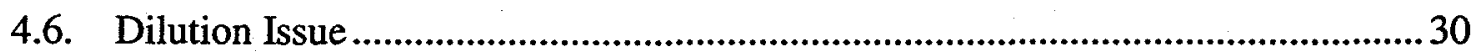

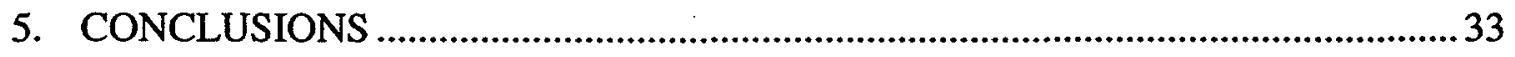

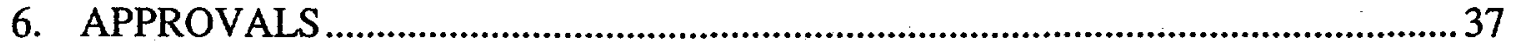

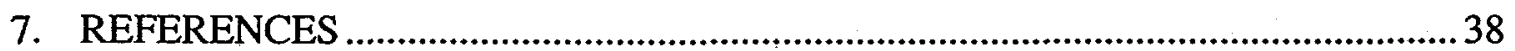

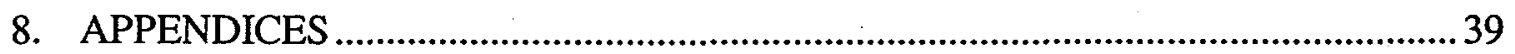

\section{INTRODUCTION}

\subsection{Background}

There were three major chemical processes used to separate plutonium, and later, plutonium and uranium, from the irradiated fuels at the Hanford Site: the bismuth phosphate, REDOX, and PUREX processes.

The bismuth phosphate batch process was the first process used. In this process, the fuel was dissolved in nitric acid and the plutonium valence was manipulated so that it coprecipitated with bismuth phosphate. This process allowed plutonium separation from uranium (which was recovered from the bismuth phosphate) and most fission products, and repetition of the cycle allowed further purification. The acidic waste was converted to a strongly alkaline solution with sodium hydroxide to prevent corrosion of the carbon steel tanks. Much of the waste generated from this process is included in Envelope B.

The REDOX process was the first continuous solvent-extraction process used at the Hanford Site. The REDOX process separated both uranium and plutonium from irradiated fuel. Uranium and plutonium were separated from fission products and held in aqueous aluminum nitrate solution by manipulating the plutonium valance so that the two actinides could be preferentially extracted with hexone (methyl isobutyl ketone). Uranium and plutonium were then separated from one another by further hexone 
extractions after plutonium valence manipulation. Much of the waste generated from this process was neutralized with sodium hydroxide and is included in Envelope A.

The third processing scheme, PUREX (plutonium-uranium extraction), separated plutonium, uranium, and neptunium from irradiated fuel and much of this waste has been classified as part of Envelope C. Using the PUREX process, 77.7 percent of the plutonium produced at Hanford was separated. Because PUREX was the most efficient process, there is more bismuth phosphate (Envelope A) and REDOX waste in the underground Hanford Tanks. The solvent extraction used tributyl phosphate (TBP) and normal paraffin hydrocarbon (NPH). During this separation process, actinides were transferred to the organic phase. There were several secondary processes of the Hanford waste. This is especially true of the REDOX and PUREX waste. Acidified PUREX waste and PUREX tank waste sludge were treated to remove strontium. Strontium was recovered in $B$ Plant with another solvent-extraction process where nitric-acid acidified waste was extracted with an organic extractant consisting of D2EHP/TBP/NPH. A purification step involving EDTA, HEDTA, and glycolate was used. Strontium was ultimately precipitated as a carbonate solid by treating the organic phase. Organic reagents were recycled and aqueous phases were sent back to tanks as waste. Similarly, much of the radioactive cesium was removed from the REDOX supernatant and PUREX supernatant in B Plant using an ion exchange process. This introduced other organic complexants, such as gluconate and HEDTA.

The TWRS Contract classifies waste to be processed by the facility into four categories: envelopes A, B, C, and D. Envelopes A, B, and C are low activity waste (LAW) supernates and Envelope D is high-level waste (HLW) sludge. The majority of the LAW that this BNFL facility will process falls into the category of Envelope A: Cesium, sulfate, and technetium must be removed from this envelope in order to meet LAW glass specification. Envelope B contains higher concentration of Cs than Envelope A. In addition to cesium, sulfate, and technetium, this envelope also contains higher concentrations of chloride, chromium, fluoride, and phosphate, which may limit the waste loading in the glass. Envelope $\mathrm{C}$ contains molar concentrations of organic compounds. The strontium and transuranics in this envelope are organically complexed and these radionuclides will require removal from the glass feed stream prior to glassification. Cesium and technetium in this envelope will need to be removed from the glass feed stream to ensure that the LAW glass specification can be met. Finally, Envelope D from the HLW slurry will be vitrified along with the radionuclides separated from Envelopes A, B, and C.

The composition of the various streams within the treatment process, as well as the feed streams, will vary greatly during pretreatment processing. Additional variation in the chemical composition of the waste stream will be introduced as a result of mixing various streams together during waste processing, due to the presence of tank heels. These variations in chemical composition may promote unfavorable conditions for waste treatment. Several potential mixing problems have already been identified in the Test Specifications for this task (Johnson 1999). 
The general objective of this work was to conduct a series of preliminary computer simulations to determine the influence of various mixing scenarios on the formation of solids, and to help define the experimental design for simulant and radioactive testing. The formation of solids during waste treatment is a concern because it may interfere with process efficiency, such as filtration and ion exchange, and may cause non-targeted radionuclides to precipitate or coprecipitate out of solution. Precipitation of solids will increase the solids burden on the filtration process. The solids from the filtration process will either be returned to DOE for storage or transferred to either the low activity or the high-level glassification processes. Therefore, predicting the amount of precipitate is critical to determining the volume of waste returned to DOE or vitrified. Another concern not addressed in this report is that the speciation of various radionuclides could be adversely affected by stream mixing. For example, technetium may be converted into a non-extractable species as a result of mixing the heel of Envelope $C$ with Envelope $A$. Radionuclide speciation was not addressed in these simulations primarily because the phenomena that may be adversely affecting radionuclide extraction are not clearly understood. Redox issues were also not addressed in these simulations because insufficient information is presently known about the redox status of the various waste streams and constituents.

The test specifications identify nine items of concern (Johnson 1999), eight of which are directly or indirectly addressed in this report. The first concern is referred to as the heel issue. It involves the formation of precipitates as a result of mixing the heel of Envelope C with Envelopes A or B (Item 1 in the Test Specification, Johnson 1999). The heel is the volume that remains in the tank after it has been drained, i.e., that portion below the outlet. The heel has been estimated to constitute $\sim 9 \%$ of the storage vessel's volume. Envelope C contains molar concentrations of total organic carbon (TOC) and may have the capacity to induce reductive precipitation as well as induce precipitation of salts not normally expected to precipitate from Envelope A. Another concern with mixing Envelope A with the heel of Envelope $C$ is that pertechnetate may be converted to a nonextractable form during reduction, thereby increasing technetium content in ILAW glass. This latter concern is not addressed in this report because the redox parameters and correct technetium speciation are not well known.

Another mixing concern is referred as the dilution issue. It involves the formation of solids as a result of diluting the various supernate feeds. Dilution of treatment streams could lower the solution $\mathrm{pH}$, resulting in solids precipitation. The supernate feed is referred to as Stream 22 in the flowsheet presented by Colebrook and Coleman (1998a, 1998b). One of their flowsheets is included in Appendix A. An example of mixing of streams that will result in significant dilution of the feed stream is where the permeate from the dewatering process of the HLW feed (Stream 20, Appendix A) is mixed with the feed stream (Stream 22). Johnson (1999) describes this as Items 2, 7, and 8 in the test specification. Another example is mixing the wash water of the LAW-entrained solids with Envelopes A, B, or C.

The "acidification" issue is concerned with the formation of solids as a result of lowering the $\mathrm{pH}$ of the stream. There are several places in the proposed flowsheet where acidic 
waste streams may be mixed with the feed, although the small volume and concentration of these streams will ensure that the feed solution never becomes acidic. These process points are outlined in the test specification as Items 3, 4, 5, and 6 (Johnson 1999). Item 3 involves the mixing of cleaning solutions from the ultrafiltration system with Envelopes $\mathrm{A}, \mathrm{B}$, or $\mathrm{C}$ feed. The cleaning solutions are dilute nitric acid solution or caustic. Mixing acidic cleaning solution with the LAW feed could lower the solution $\mathrm{pH}$, resulting in the formation of precipitates, acid-base reaction, and affect separation of radionuclides. Item 5 involves the mixing of the HLW melter off-gas condensate with Envelope D (Stream 170 mixed with Stream 18; Appendix A). The melter off-gas condensate is potentially acidic. Item 6 involves the mixing of LAW melter off-gas condensate (Stream 91; Appendix A) with pretreated LAW feed to the evaporator (Stream 13) and the mixing of LAW melter off-gas condensate (Stream 91) with LAW feed (Stream 22). Item 8 involves the mixing of Sr/TRU-precipitate wastewater with Envelopes A, B, or C feed.

Item 9 addresses the possible reduction of technetium by an ion exchange resin. This item is outside the scope of the mixing studies and will be addressed with experiments with actual waste.

Finally, there is concern regarding the influence of various organic compounds on stream tendency to form precipitates. Measurement of organic compounds in the tank waste is very difficult, resulting in great uncertainty regarding their composition and concentrations. The types of precipitates formed and the propensity of the various organic compounds (such as acetate, formate, glycolate, and oxalate) to form precipitates is not understood well (Barney 1994, 1995, 1996; Orme 1998).

\subsection{Objectives}

The specific objectives of this study were to evaluate the influence of the following mixing scenarios on the formation of precipitates:

- mixing Envelope C with Envelope A, i.e., the heel issue (Item 1 in the test specifications; Johnson [1999]),

- mixing a dilute wash stream with Envelope A, i.e., the dilution issue (related to Items 2, 7, and 8 in the test specifications; Johnson [1999]),

- mixing varying concentrations of $\mathrm{HNO}_{3}$ with Envelope A, i.e., the acidity issue (related to Items 3, 4, and 5 in the test specifications; Johnson [1999]).

Additionally, the influence of various organic compounds on the formation of solids in Envelope A was evaluated.

\subsection{Scope}

This is the first phase of our modeling effort. The intent of this work was to provide a first approximation of the effect of stream mixing and waste stream composition on precipitation. The other intent is to provide guidance for designing subsequent laboratory studies. This work will provide the basis for more refined modeling that will include data 
generated from laboratory studies. The emphasis of this study was to identify the conditions for which precipitation of solids in Envelope A was predicted.

These simulations do not address several key mixing issues, including radionuclide speciation, coprecipitation, and redox chemistry. These issues were not addressed because either not enough information is presently available about the chemical reactions potentially occurring (e.g., the conversion of pertechnetate to non-extractable forms of technetium), or insufficient analytical data are available to model the process (e.g., redox chemistry and coprecipitation). If subsequent experiments can generate these data, additional modeling of these important reactions will be conducted.

Coprecipitation will occur in the treatment system. For example, coprecipitation of several metals, including $\mathrm{U}$ and $\mathrm{Sr}$, in carbonate phases is likely. Unfortunately, there are presently no robust models that can accurately predict coprecipitation in brines. Again, modeling this process is very important but would be premature without supporting experimental data.

Redox reactions may have a profound influence on process chemistry. The extent of this effect is not known and the oxidizing and reducing constituents in the waste stream have not been identified. Without this information, there is a high degree of uncertainty in modeling these redox reactions. Redox reactions can not be modeled without this information because the resulting answers are dictated by the choice of redox couples and their assigned concentrations (the OLI model, described below, the redox potential is set by the concentrations the user assigns to the controlling redox couple).

\subsection{Quality Assurance}

This document was prepared as a scoping activity as defined in the WSRD QA Manual 1Q Procedure QAP 2-3. The results are to be considered estimates of the chemical behavior and conditions. The results are not suitable as a basis for safety design parameters.

\section{EXPERIMENTAL}

The OLI chemical speciation model was used in these calculations (OLI Software Systems, 1996). Briefly, OLI is a robust speciation model that can conduct unit-type simulations and flowsheet-type simulations. It has a thermodynamic framework that predicts complex aqueous-based chemistry in equilibrium with optional vapor, nonaqueous liquid, and solid phases. The aqueous model is predictive over the general range of 0 to $300^{\circ} \mathrm{C}, 0$ to $1500 \mathrm{bar}$ and 0 to 30 (molal) ionic strength. The OLI databank is extensive, containing physical constants for over $>3000$ inorganic and organic species. The predictive framework is based upon:

- the Revised Helgeson Equation of State for predicting the standard state thermodynamic properties of all species, including organics, in water; 
- the Bromley-Zemaitis framework for the prediction of excess thermodynamic properties;

- the Pitzer and Setschenow formulation for the prediction of the excess thermodynamic properties calculation of molecular species in water; and

- the Enhance SRK Equation of State for the prediction of vapor and nonaqueous, liquid-phase thermodynamic properties.

Most of the Hanford waste tank stream composition data used in these simulations was obtained from Colebrook and Coleman (1998a, 1998b). Colebrook and Coleman (1998a, 1998b) conducted early flowsheet calculations using the chemistries of Tank AW-101 as a typical Envelope A waste form and Tank AN-107 as a typical Envelope C waste form. The chemistries of these waste forms were based on tank waste characterization reports. These data generally reported total organic carbon (TOC). Since TOC is not an actual chemical specie, it was necessary to convert this measurement into constituents that are meaningful to OLI. The organic constituents and their respective concentrations for Envelope A and Envelope C were taken from Eibling (1998) and Johnson (1998).

Additional information about the organic composition of the two envelopes was obtained from tank characterization data. Additional details of the treatment of organic components in the simulations are presented in the Organic Compounds in Envelope A section below.

One of the limitations of OLI is that it can accommodate only 50 salts in the aqueous phase. By way of explanation, OLI converts analytical results, such as ICP-AES or IC data, into salts prior to conducting speciation calculations. It is these salt constructs that can not exceed 50. This means that several constituents known to exist in the feed solutions had to be eliminated from the simulated waste stream. Several factors were considered in the selection criteria for eliminating constituents from the simulated waste stream. Since the mass of precipitates was among the most important output concerns, the constituents with low concentrations were removed (e.g., Ba, Cd, Hg, La, Mn, Ni, $\mathrm{UO}_{2}{ }^{+2}$, and $\mathrm{Pb}$ ). Constituents with low concentrations and low solubility products were eliminated (e.g., lithium). Constituents that had low concentration and required OLI to form several salt constructs were also eliminated (e.g., $\mathrm{Hg}, \mathrm{Pb}$, and $\mathrm{UO}_{2}{ }^{2+}$ ).

One of the calculations that OLI conducts prior to assigning constituents (e.g., chloride or total calcium) to salts is to alter the inputted concentrations to maintain charge balance. This was accomplished by adding either $\mathrm{Na}^{+}$or $\mathrm{NO}_{3}{ }^{-}$to a given stream. Sodium was selected because it is by far the most dominant cation in the system. Nitrate was selected because its reported concentrations varies the most among the anions included in the tank characterization data and it existed generally in very high concentrations, second only to hydroxide concentrations. For example, $\mathrm{NO}_{3}{ }^{-}$concentrations in tank $241-\mathrm{AN}-103$ classified as "liquid" (which includes supernatant) varied by at least three-orders of magnitude, from $4.08 \mathrm{M}$ to $7.4 \mathrm{e}-3 \mathrm{M}$. The $\mathrm{NO}_{3}{ }^{-}$concentration may in fact vary greatly in the waste tanks. Hydroxides were not selected because the variability of $\mathrm{OH}^{-}$ concentration was appreciably less. The measured free hydroxide concentration of actual waste is considered reliable. 
For the most part, the original OLI model and data package were used for these calculations. OLI was modified to permit gluconate to be entered into calculations; specifically, gluconate was included in the WATER ANALYZER portion of the program. Secondly, the system was modeled to include equilibration with $\mathrm{CO}_{2}$ (gas) in the air. Gaseous $\mathrm{CO}_{2}$ was included in these simulations because its solubility increases as aqueous hydroxide concentrations increase.

Perhaps the single most important limitation of the thermodynamic approach to estimating chemical speciation is that knowledge of the predicted solids is frequently not available. Typically, thermodynamic calculations over-estimate the extent of actual precipitation because kinetic limitations are not taken into consideration. Thus, solid phases that require geologic timeframes to be formed are "formed" instantly in thermodynamic models. Kinetic limitations to the formation of solids are common in ephemeral systems, such as waste streams. Some redox and absorption reactions are typically slow and may take days or weeks to come to equilibrium, a long duration in the context of waste processing.

Although tens of thousands of constants are included in the OLI Public Database, some constants that will be needed for future calculations are missing, including several technetium constants of interest to this project. Efforts will be directed in the next phase of this modeling task to collect these data. 


\section{RESULTS and DISCUSSIONS}

\subsection{Envelope A}

Envelope A feed stream was based on the composition of Tank AW-101 and was included in each of the simulations. The composition of the supernatant and solids reported by Colebrook and Coleman (1998a, 1998b) are presented in Table 1. As mentioned in the Experimental section above, OLI could not accommodate all the constituents known to exist in the various envelopes. Consequently, several supernatant constituents were eliminated based on the criteria discussed above and the results are presented in Table 2. All the radionuclides were eliminated from the simulated waste. The baseline simulated feed stream used throughout these calculations, except were noted, contained a total organic carbon (TOC) content of $0.299 \mathrm{M}$. The TOC was converted on a carbon equivalent basis into formate (or for a few simulations, into oxalate, formate and glycolate). Of the organic compounds in Envelope A, formate exists in the highest concentration. Oxalate exists in appreciably lower concentrations but has a solubility that is $>1000$ lower than the other dominant organic compounds in Envelope A (acetate, formate, and glycolate). Additional discussion of the organic compounds in the waste stream will be discussed in the following section entitled "Organic Compounds in Envelope A." Sodium, aluminum, and potassium accounted for $>99.99 \%$ of the total molar cation concentration in the simulated stream; sodium alone accounts for $87 \%$ of the total cation molar concentration. Similarly, hydroxide, nitrate, nitrite, carbonate, and chloride concentrations account for $>98 \%$ of the total anion molar concentration in the stream; hydroxide accounts for $45 \%$, nitrate for $28 \%$. Total organic carbon accounted for $<1 \%$ of the total anion molar concentration. 
Table 1. Aqueous and Solid Composition of Envelope A (Colebrook and Coleman 1998a, $\left.1998 b^{(a)}\right)$

\begin{tabular}{|c|c|c|c|c|c|c|c|}
\hline $\begin{array}{l}\text { Aqueous } \\
\text { Non-rad }\end{array}$ & $\begin{array}{l}\text { Conc. } \\
(\mathrm{mol} / \mathrm{L})\end{array}$ & $\begin{array}{l}\text { Aqueous } \\
\text { Rad }\end{array}$ & $\begin{array}{l}\text { Activity } \\
(\mathrm{Bq} / \mathrm{L})\end{array}$ & $\begin{array}{l}\text { Solid } \\
\text { Rad }\end{array}$ & $\begin{array}{c}\text { Activity } \\
\mathrm{Bq} / \mathrm{g}\end{array}$ & $\begin{array}{l}\text { Solids } \\
\text { Non-rad }\end{array}$ & $\begin{array}{c}\text { Mass } \\
\text { Fraction }\end{array}$ \\
\hline Al & 0.904 & Sr-90 & $3.700 \mathrm{E}+07$ & Cs-137 & $1.300 \mathrm{E}+07$ & $\mathrm{Na}_{2} \mathrm{O}(\mathrm{s})$ & 0.385 \\
\hline $\mathrm{Ba}$ & $2.600 \mathrm{E}-06$ & Tc-99 & $5.370 \mathrm{E}+06$ & Sr-90 & $1.310 \mathrm{E}+07$ & $\mathrm{~K}_{2} \mathrm{O}(\mathrm{s})$ & 0.01 \\
\hline $\mathrm{Ca}$ & $1.050 \mathrm{E}-03$ & Cs- 137 & $1.370 \mathrm{E}+10$ & Tc-99 & $2.720 \mathrm{E}+05$ & $\mathrm{Al}_{2} \mathrm{O}_{3}(\mathrm{~s})$ & 0.093 \\
\hline $\mathrm{Cd}$ & $2.600 \mathrm{E}-05$ & Pu-239 & $3.480 \mathrm{E}+04$ & Am-24l & $6.850 \mathrm{E}+05$ & $\mathrm{CaO}(\mathrm{s})$ & 0.037 \\
\hline $\mathrm{Cr}$ & $1.970 \mathrm{E}-03$ & $\mathrm{Pu}-240$ & $3.480 \mathrm{E}+04$ & Co-60 & $5.400 \mathrm{E}+04$ & $\mathrm{Cr}_{2} \mathrm{O}_{3}(\mathrm{~s})$ & 0.044 \\
\hline $\mathrm{Fe}$ & $3.750 \mathrm{E}-04$ & $\mathrm{Pu}-241$ & NA & Eu-154 & $2.820 \mathrm{E}+05$ & $\mathrm{Fe}_{2} \mathrm{O}_{3}(\mathrm{~s})$ & 0.047 \\
\hline $\mathrm{Hg}$ & $2.700 \mathrm{E}-07$ & Am-241 & $6.960 \mathrm{E}+04$ & $\mathrm{Eu}-155$ & $3.810 \mathrm{E}+05$ & $\mathrm{Ni}_{2} \mathrm{O}_{3}(\mathrm{~s})$ & 0.0048 \\
\hline K & $9.200 \mathrm{E}-01$ & $\mathrm{Co}-60^{(\mathrm{b})}$ & $8.510 \mathrm{E}+05$ & $\mathrm{Pu}-238$ & $3.550 \mathrm{E}+05$ & $\mathrm{MgO}(\mathrm{s})$ & 0.011 \\
\hline $\mathrm{La}$ & $4.300 \mathrm{E}-07$ & $\mathrm{Eu}-154^{(\mathrm{b})}$ & $2.780 \mathrm{E}+06$ & $\mathrm{Pu}-239$ & $1.095 \mathrm{E}+05$ & $\mathrm{SiO}_{2}(\mathrm{~s})$ & 0.193 \\
\hline $\mathrm{Mn}$ & $1.830 \mathrm{E}-04$ & $\mathrm{Eu}-155^{(\mathrm{b})}$ & $1.500 \mathrm{E}+07$ & $\mathrm{Pu}-240$ & $1.095 \mathrm{E}+05$ & $\mathrm{ZrO}_{2}(\mathrm{~s})$ & 0.175 \\
\hline $\mathrm{Na}$ & $\begin{array}{c}9.000 \mathrm{E}+0 \\
0\end{array}$ & & & & & $\mathrm{Pu}(\mathrm{s})$ & 0 \\
\hline $\mathrm{Ni}$ & $1.740 \mathrm{E}-04$ & & & & & & \\
\hline $\mathrm{Pb}$ & $2.780 \mathrm{E}-04$ & & & & & & \\
\hline $\mathrm{U}$ & $1.190 \mathrm{E}-04$ & & & & & & \\
\hline $\begin{array}{l}\mathrm{CO}_{3} \\
\text { (TIC) }\end{array}$ & 0.380 & & & & & & \\
\hline $\mathrm{Cl}$ & 0.140 & & & & & & \\
\hline$F$ & 0.027 & & & & & & \\
\hline $\mathrm{SO}_{4}$ & 0.0063 & & & & & & \\
\hline $\mathrm{NO}_{3}$ & 2.91 & & & & & & \\
\hline $\mathrm{NO}_{2}$ & 1.95 & & & & & & \\
\hline $\mathrm{PO}_{4}$ & 0.015 & & & & & & \\
\hline Free OH & 4.65 & & & & & & \\
\hline TOC & 3.36 & & & & & & \\
\hline Total & 24.27 & Total & $1.376 \mathrm{E}+10$ & Total & $2.835 E+07$ & Total & 1.000 \\
\hline
\end{tabular}


Table 2. Constituents Included in Simulated Envelope $A^{(a)}$

\begin{tabular}{ccc}
\hline $\begin{array}{c}\text { Aqueous } \\
\text { Non-rad }\end{array}$ & $\begin{array}{c}\text { Concentration } \\
(\text { mol/L) }\end{array}$ & Comments $^{(\mathbf{b})}$ \\
$\mathrm{Al}$ & $9.04 \mathrm{E}-01$ & 1 \\
$\mathrm{Ba}$ & $2.60 \mathrm{E}-06$ & 1 \\
$\mathrm{Ca}$ & $1.05 \mathrm{E}-03$ & \\
$\mathrm{Cd}$ & $2.60 \mathrm{E}-05$ & \\
$\mathrm{Cr}$ & $1.97 \mathrm{E}-03$ & 1 \\
$\mathrm{Fe}$ & $3.75 \mathrm{E}-04$ & \\
$\mathrm{Hg}$ & $2.70 \mathrm{E}-07$ & 1 \\
$\mathrm{~K}$ & 0.92 & 1 \\
$\mathrm{La}$ & $4.30 \mathrm{E}-07$ & 1 \\
$\mathrm{Mn}$ & $1.83 \mathrm{E}-04$ & 1,2 \\
$\mathrm{Na}$ & 9 & 1 \\
$\mathrm{Ni}$ & $1.74 \mathrm{E}-04$ & \\
$\mathrm{~Pb}$ & $2.78 \mathrm{E}-04$ & \\
$\mathrm{U}$ & $1.19 \mathrm{E}-04$ & \\
$\mathrm{CO}_{3}(\mathrm{TIC})$ & 0.38 & \\
$\mathrm{Cl}$ & 0.14 & \\
$\mathrm{~F}$ & 0.027 & \\
$\mathrm{SO}_{4}$ & $6.30 \mathrm{E}-03$ & 3 \\
$\mathrm{NO}_{3}$ & 2.91 & \\
$\mathrm{NO}_{2}$ & 1.95 & 3 \\
$\mathrm{PO}_{4}$ & $1.50 \mathrm{E}-02$ & \\
$\mathrm{Free}_{\mathrm{OH}}$ & 4.65 & \\
$\mathrm{TOC}$ & 0.299 & \\
$\mathrm{Formate}$ & $6.40 \mathrm{E}-02$ & \\
$\mathrm{Oxalate}$ & $6.93 \mathrm{E}-03$ & \\
\hline
\end{tabular}

(a) Based on chemistry of Tank AW-101; see Table 1.

(b) Comments:

1. Dropped constituent because it has a low concentration.

2. Dropped constituent because it had low concentration and its presence in the simulated stream induced OLI to invoke large number of salts, thereby greatly decreasing number of components that could be evaluated in a single simulation.

3. Expressed TOC as either formate or oxalate. These organic compounds were selected to represent TOC because they exist in high concentrations in Envelope $A$ and because there are many formate and oxalate constants in OLI Public Database. TOC concentration data from Eibling (1998), which describes the chemistry of Tank AW101. 


\subsection{Envelope C}

Envelope $C$ waste was generated primarily from the separation of cesium and strontium at the Hanford Site. Strontium separation at the B Plant located in the Hanford Site was achieved by complexation with EDTA, HEDTA, and glycolate. Strontium was ultimately precipitated as a carbonate solid by treating the organic phase. Cesium was separated from tank and process waste by two principle methods: adsorption onto zeolite or organic resin columns and treatment of acidified PUREX waste liquor with phosphotungstic acid to form a Cs-bearing precipitate. The resulting aqueous wastes from the strontium and cesium separation processing were sent back to the tanks after neutralization of residual acid.

The primary chemical differences between Envelopes $\mathrm{A}$ and $\mathrm{C}$ are that the latter contains appreciably higher concentrations of total organic carbon and lower concentrations of aluminum, lanthanum, and free hydroxide (Tables 1 and 3). Total radionuclide activity in the supernatant and in the solids is about the same in the two envelopes. The composition of Envelope $\mathrm{C}$ feed stream was based on the composition of Tank AN-107 (Colebrook and Coleman 1998a, 1998b).

Because OLI is restricted to only 50 salts in the aqueous phase, several supernatant constituents known to exist in Envelope $C$ had to be eliminated from the OLI calculations. The elimination process is described in the Methods Section of this report and is outlined in Table 4. 
Table 3. Composition of Envelope C (Colebrook and Coleman 1998a 1998b) ${ }^{(a)}$

\begin{tabular}{|c|c|c|c|c|c|c|c|}
\hline $\begin{array}{l}\text { Aqueous } \\
\text { Non-rad }\end{array}$ & $\begin{array}{c}\text { Conc. } \\
(\mathrm{mol} / \mathrm{L})\end{array}$ & $\begin{array}{l}\text { Aqueous } \\
\text { Rad }\end{array}$ & $\begin{array}{l}\text { Activity } \\
(\mathrm{Bg} / \mathrm{L})\end{array}$ & $\begin{array}{l}\text { Solid } \\
\text { Rad } \\
\end{array}$ & $\begin{array}{c}\text { Activity } \\
\mathrm{Bg} / \mathrm{g}\end{array}$ & $\begin{array}{l}\text { Solids } \\
\text { Non-rad }\end{array}$ & $\begin{array}{c}\text { Mass } \\
\text { Fraction }\end{array}$ \\
\hline$\overline{\mathrm{Al}}$ & $1.40 \mathrm{E}-02$ & Sr-90 & $2.02 \mathrm{E}+09$ & Cs-137 & $1.30 \mathrm{E}+07$ & $\mathrm{Na}_{2} \mathrm{O}(\mathrm{s})$ & 0.385 \\
\hline $\mathrm{Ba}$ & $1.50 \mathrm{E}-04$ & Tc-99 & $4.74 \mathrm{E}+06$ & Sr-90 & $1.31 E+07$ & $\mathrm{~K}_{2} \mathrm{O}(\mathrm{s})$ & $1.00 \mathrm{E}-02$ \\
\hline $\mathrm{Ca}$ & $1.50 \mathrm{E}-02$ & Cs- 137 & $1.20 \mathrm{E}+10$ & Tc-99 & $2.72 E+05$ & $\mathrm{Al}_{2} \mathrm{O}_{3}(\mathrm{~s})$ & 0.093 \\
\hline $\mathrm{Cd}$ & $5.70 \mathrm{E}-04$ & Pu-239 & $8.53 E+05$ & Am-241 & $6.85 E+05$ & $\mathrm{CaO}(\mathrm{s})$ & $3.70 \mathrm{E}-02$ \\
\hline $\mathrm{Cr}$ & $3.39 \mathrm{E}-03$ & $\mathrm{Pu}-240$ & $8.53 E+05$ & Co-60 & $5.40 E+04$ & $\mathrm{Cr}_{2} \mathrm{O}_{3}(\mathrm{~s})$ & 0.044 \\
\hline $\mathrm{Fe}$ & $3.00 \mathrm{E}-02$ & $\mathrm{Pu}-241$ & NA & Eu-154 & $2.82 E+05$ & $\mathrm{Fe}_{2} \mathrm{O}_{3}(\mathrm{~s})$ & 0.047 \\
\hline $\mathrm{Hg}$ & $2.50 \mathrm{E}-06$ & Am-241 & $2.04 E+07$ & Eu-155 & $3.81 \mathrm{E}+05$ & $\mathrm{Ni}_{2} \mathrm{O}_{3}(\mathrm{~s})$ & $4.80 \mathrm{E}-03$ \\
\hline $\begin{array}{l}\mathrm{K} \\
\mathrm{La}\end{array}$ & $\begin{array}{c}0.05 \\
3.30 \mathrm{E}-04\end{array}$ & $\begin{array}{l}\text { Co-60 } \\
\text { Eu-154 }\end{array}$ & $\begin{array}{l}7.29 \mathrm{E}+06 \\
3.10 \mathrm{E}+07\end{array}$ & $\begin{array}{l}\text { Pu-238 } \\
\text { Pu-239 }\end{array}$ & $\begin{array}{l}3.55 E+05 \\
1.10 E+05\end{array}$ & $\begin{array}{l}\mathrm{MgO}(\mathrm{s}) \\
\mathrm{SiO}_{2}(\mathrm{~s})\end{array}$ & $\begin{array}{c}1.10 \mathrm{E}-02 \\
0.193\end{array}$ \\
\hline $\mathrm{Mn}$ & $1.00 \mathrm{E}-02$ & Eu-155 & $5.14 \mathrm{E}+07$ & $\mathrm{Pu}-240$ & $1.10 E+05$ & $\mathrm{ZrO}_{2}(\mathrm{~s})$ & 0.175 \\
\hline $\mathrm{Na}$ & 8.48 & & & & & $\mathrm{Pu}(\mathrm{s})$ & 0 \\
\hline $\mathrm{Ni}$ & $9.00 \mathrm{E}-03$ & & & & & & \\
\hline $\begin{array}{l}\mathrm{Pb} \\
\mathrm{U}\end{array}$ & $\begin{array}{l}1.87 \mathrm{E}-03 \\
6.90 \mathrm{E}-04\end{array}$ & & & & & & \\
\hline $\mathrm{CO}_{3}(\mathrm{TIC})$ & 1.09 & & & & & & \\
\hline $\mathrm{Cl}$ & $5.20 \mathrm{E}-02$ & & & & & & \\
\hline $\mathrm{F}$ & $7.00 \mathrm{E}-03$ & & & & & & \\
\hline $\mathrm{SO}_{4}$ & $8.60 \mathrm{E}-02$ & & & & & & \\
\hline $\mathrm{NO}_{3}$ & 3.71 & & & & & & \\
\hline $\mathrm{NO}_{2}$ & 1.33 & & & & & & \\
\hline $\mathrm{PO}_{4}$ & $1.20 \mathrm{E}-02$ & & & & & & \\
\hline Free OH & 0.04 & & & & & & \\
\hline TOC & 3.36 & & & & & & \\
\hline Total & 18.31 & Total & $1.41 E+10$ & Total & $2.83 E+07$ & Total & 1.000 \\
\hline
\end{tabular}


Table 4. Constituents Included in Simulated Envelope C

\begin{tabular}{ccc}
\hline $\begin{array}{c}\text { Aqueous } \\
\text { Non-rad }\end{array}$ & $\begin{array}{c}\text { Concentration } \\
(\text { mol/L) }\end{array}$ & Comments $^{(\text {a) }}$ \\
\hline $\mathrm{Al}$ & $1.40 \mathrm{E}-02$ & 1 \\
$\mathrm{Ba}$ & $1.50 \mathrm{E}-04$ & \\
$\mathrm{Ca}$ & $1.50 \mathrm{E}-02$ & 1 \\
$\mathrm{Cd}$ & $5.70 \mathrm{E}-04$ & 1 \\
$\mathrm{Cr}$ & $3.39 \mathrm{E}-03$ & 1,2 \\
$\mathrm{Fe}$ & $3.00 \mathrm{E}-02$ & \\
$\mathrm{Hg}$ & $2.50 \mathrm{E}-06$ & 1 \\
$\mathrm{~K}$ & 0.05 & \\
$\mathrm{La}$ & $3.30 \mathrm{E}-04$ & 1 \\
$\mathrm{Mn}$ & $1.00 \mathrm{E}-02$ & 1,2 \\
$\mathrm{Na}$ & 8.48 & 1 \\
$\mathrm{Ni}$ & $9.00 \mathrm{E}-03$ & \\
$\mathrm{~Pb}$ & $1.87 \mathrm{E}-03$ & 1 \\
$\mathrm{U}$ & $6.90 \mathrm{E}-04$ & \\
$\mathrm{CO}_{3}(\mathrm{TIC})$ & 1.09 & \\
$\mathrm{Cl}$ & $5.20 \mathrm{E}-02$ & \\
$\mathrm{~F}$ & $7.00 \mathrm{E}-03$ & \\
$\mathrm{SO}_{4}$ & $8.60 \mathrm{E}-02$ & \\
$\mathrm{NO}$ & 3.71 & 3 \\
$\mathrm{NO}$ & 1.33 & 3 \\
$\mathrm{PO}$ & $1.20 \mathrm{E}-02$ & 3 \\
$\mathrm{Free}_{3} \mathrm{OH}$ & 0.04 & \\
$\mathrm{TOC}$ & 3.36 & \\
$\mathrm{Formate}^{2}$ & 1.584 & \\
$\mathrm{Glycolate}^{2}$ & 0.792 & \\
\hline
\end{tabular}

(a) Comments:

1) Dropped constituent because it has a low concentration.

2) Dropped constituent because it had low concentration and its presence in the simulated stream induced OLI to invoke large number of salts, thereby greatly decreasing number of components that could be evaluated in a single simulation.

3) TOC is not a constituent in OLI. EDTA, formate, and glycolate are not included in the Envelope C chemical compositions presented by Colebrook and Coleman (1998a, 1998b, Table 3 in this report). TOC was represented on a carbon mass basis as 50\% formate and $50 \%$ glycolate. These organic compounds were selected to represent TOC because they each account for the highest percentages of carbon in envelope $\mathrm{C}$ (WSRC 1998a, 1998b, PNNL 1998). Concentration data for TOC, EDTA, formate, and glycolate is from WSRC $1998 \mathrm{~b}$. 


\subsection{Organic Compounds in Envelope A}

Analytical data related to the organic compounds in Envelope A are reported in terms of total organic carbon, and to a limited extent, of the individual compounds within the various tanks. Table 5 contains the average concentration for all the organic compounds and the total organic carbon measured in Tank AW-101, part of Envelope A. The concentration of oxalate is approximately an order of magnitude less than that of acetate, formate, and glycolate. The second to last column of Table 5 shows that the measured organic compounds account for $65 \%$ of the total organic carbon. This is a surprisingly good mass balance considering the complexity of the system and the difficulty of the analytical procedure. The last column of the table shows the weighed percentages of the four compounds normalized to the measured total organic carbon. This later calculation was conducted to provide an index of the proportion of the individual organic constituents, and was not meant to provide an index of the actual expected concentrations. It is quite likely that the majority of the $35 \%$ of carbon not accounted for by the acetate, formate, glycolate, and oxalate is associated with other compounds. Chemical and radiolytic degradation of organic compounds has likely produced a complex array of organic degradation products.

Table 5. Estimated Organic Compound Concentrations in Tank AW-101, Envelope $A^{(a)}$

\begin{tabular}{|c|c|c|c|c|c|c|c|}
\hline Component & $\begin{array}{c}\text { Formula } \\
\text { Weight }\end{array}$ & $\begin{array}{c}\text { Conc. } \\
(\mathrm{mg} \mathrm{C} / \mathrm{L})\end{array}$ & $\begin{array}{l}\text { Conc. } \\
\text { (M) }\end{array}$ & $\begin{array}{c}\text { \#C atoms/ } \\
\text { Formula } \\
\text { Weight }\end{array}$ & $\begin{array}{l}\text { Carbon } \\
(\mathrm{mg} / \mathrm{L})\end{array}$ & $\begin{array}{c}\% \text { of TOC } \\
\text { based on } \\
\text { equivalent C }\end{array}$ & $\begin{array}{c}\% \text { Normal- } \\
\text { ized to } \\
\text { TOC }(\%)\end{array}$ \\
\hline Acetate & 59.04 & 2070 & 0.0351 & 2 & 843.2 & 24 & 36.2 \\
\hline Formate & 45.02 & 2880 & 0.0640 & 1 & 768.7 & 21 & 33.0 \\
\hline Glycolate & 75.04 & 1150 & 0.0153 & 3 & 551.3 & 15 & 23.7 \\
\hline Oxalate & 88.02 & 610 & 0.0069 & 2 & 166.5 & 5 & 7.1 \\
\hline TOC & & 3590 & & & & & \\
\hline Total & & & & & & 65 & 100 \\
\hline \multicolumn{8}{|c|}{$\begin{array}{l}\text { All concentration data taken from Eibling (1998). Acetate, formate, and oxalate } \\
\text { concentration data from Tank AW-101 (as reported originally by Esch [1996a]). TOC } \\
\text { concentration value is from Part A, Tank AN-101 (as reported originally by Esch [1996b]). } \\
\text { Glycolate concentration estimated by Eibling (1998) and was based on "less-than" } \\
\text { concentration measured values (as reported originally by Esch [1996a]). }\end{array}$} \\
\hline
\end{tabular}

Until recently, there was little information reported in the literature pertaining to the solubility of these low molecular weight organic compounds in waste-like matrices. The solubility of many process chemicals and likely degradation products has now been reported (Barney 1994, 1995, 1996). More recently, Barney reported the solubility of formate, acetate, glycolate, NTA, EDTA, citrate, and oxalate, believed to be the most prominent organic compounds (Barney 1997). Table 6 compares their solubility values in simulated waste matrices that are saturated in sodium nitrate. Citrate, NTA, and 
EDTA are included in Table 6 because they exist in Envelope $C$ and will be discussed below with regards to the heel issue. Of the dominant organic compounds in Envelope A, oxalate has by far the lowest solubility values. Thus, it is not surprising that the concentration of oxalate is lower than those of the other organic supernate solutions (Table 5). The oxalate concentration in Table 5 is slightly greater than the solubility value in Table 6 . The cause for this inconsistency is not known, but may be attributed to differences in the background electrolytes between the two solutions and less-thanperfect analytical precision of either value.

Table 6. Solubility of Important Organic Compounds in Waste Simulants (Barney 1997)

\begin{tabular}{lll}
\hline Organic Anion & Range of Solubility $(\mathrm{mol} / \mathrm{L})$ & Equivalent grams TOC/L \\
\hline Formate & 6.6 to 8.5 & 79 to 102 \\
Acetate & 3.8 to 5.4 & 91 to 130 \\
Glycolate & 3.6 to 4.2 & 86 to 101 \\
NTA & 0.81 to 1.2 & 58 to 86 \\
EDTA & 0.83 to 1.0 & 100 to 120 \\
Citrate & 0.42 to 0.63 & 25 to 45 \\
Oxalate & 0.0012 to 0.0039 & 0.029 to 0.094 \\
\hline
\end{tabular}

${ }^{\text {(a) }}$ Solubilities were measured over the temperature range 25 to $50^{\circ} \mathrm{C}$ and over the $\mathrm{NaOH}$ concentration range of 0.06 to $1.0 \mathrm{~mol} / \mathrm{L}$.

A series of simulations were conducted in which the concentration of acetate, formate, glycolate, and oxalate of separate solutions were set equal to the total organic carbon. In the first set of simulations, the TOC was assumed to be from a single compound and was set to the average TOC value for Envelope A, $0.299 \mathrm{~mol} / \mathrm{L}$, (Table 7). In the second set of simulations, the TOC was assumed to be from a single compound and was elevated to $3.36 \mathrm{~mol} / \mathrm{L}$, an arbitrary large value selected to evaluate the sensitivity of the resulting chemistry to TOC levels (Table 8).

When TOC was set to $0.299 \mathrm{~mol} / \mathrm{L}$, the $\mathrm{pH}$ and the ionic strength of these solutions do not vary greatly (Table 7). Approximately one third of the moles in the input aqueous phase were in the solid phase. This should not be the case because the data used in these simulations were intended to represent the supernatant of the tank waste. This apparent inconsistency can be attributed to: 1) using average analytical concentrations in the simulated stream composition, 2) reconciling the simulated solution for charge neutrality, 3) using incorrect thermodynamic constants (e.g., activity corrections, temperature corrections, and association constants), and 4) the general tendency of thermodynamic models to over predict the extent of precipitation as a result of assuming instantaneous equilibrium. The concentration of the individual and total solids in the acetate, formate and glycolate solutions were nearly identical. The oxalate solution had approximately $4 \%$ greater solids, mostly attributed to the presence of Na-oxalate $\left(\mathrm{Na}_{2} \mathrm{C}_{2} \mathrm{O}_{4}\right)$. The fact that the Envelope A solution containing oxalate had more solids than the other Envelope A solutions is qualitatively consistent with solubility data of Orme in Table 6 . 
The large concentrations of $\mathrm{NaNO}_{3}$ precipitates calculated in these simulations (Table 7) are consistent with experimental results of Reynolds and Herting (1984). They reported that this precipitate accounted for a large fraction of the "salt cakes" that they characterized. Sodium nitrate precipitates often form at very high ionic strengths ( $>6 \mathrm{M}$ $\mathrm{Na}^{+}$). Orme (1998) conducted OLI simulations of Envelope B (Tank 241-AZ-101) and reported $\mathrm{NaNO}_{3}$ solids formation.

Table 7. $\mathrm{pH}$, Ionic Strength, and Precipitates Formed in Simulated Envelope A When all the Carbon is Assigned to Acetate, Formate, Glycolate, or Oxalate (TOC $=0.299 \mathrm{~mol} / \mathrm{L})^{(\mathrm{a})}$

\begin{tabular}{lccccc}
\hline & & Acetate & Formate & Glycolate & Oxalate \\
\hline $\mathrm{pH}$ & unitless & 16.2 & 16.2 & 16.2 & 16.2 \\
Ionic Strength & unitless & 17.5 & 17.5 & 17.5 & 17.4 \\
$\mathrm{NaF}$ & $\mathrm{mol} / \mathrm{L}$ & 0.027 & 0.027 & 0.027 & 0.027 \\
$\mathrm{NaNO}_{3}$ & $\mathrm{~mol} / \mathrm{L}$ & 3.005 & 3.009 & 3.018 & 3.032 \\
$\mathrm{Ca}(\mathrm{OH})_{2}$ & $\mathrm{~mol} / \mathrm{L}$ & 0.002 & 0.002 & 0.002 & 0.002 \\
$\mathrm{KNO}_{3}$ & $\mathrm{~mol} / \mathrm{L}$ & 1.174 & 1.173 & 1.167 & 1.205 \\
$\mathrm{Na}_{3} \mathrm{FSO}_{4}$ & $\mathrm{~mol} / \mathrm{L}$ & 0.008 & 0.008 & 0.008 & 0.008 \\
$\mathrm{NaCl}$ & $\mathrm{mol} / \mathrm{L}$ & 0.001 & 0 & 0.004 & 0 \\
$\mathrm{NaNO}_{2}$ & $\mathrm{~mol} / \mathrm{L}$ & 1.825 & 1.792 & 1.840 & 1.789 \\
$\mathrm{Na}_{2} \mathrm{C}_{2} \mathrm{O}_{4}$ & $\mathrm{~mol} / \mathrm{L}$ & 0 & 0 & 0 & 0.243 \\
Total solids & $\mathrm{mol} / \mathrm{L}$ & 6.042 & 6.011 & 6.066 & 6.306 \\
\hline
\end{tabular}

(a) The composition of Simulated Envelope $\mathrm{A}$ is presented in Table 2.

As expected, when the TOC was set to $3.36 \mathrm{~mol} / \mathrm{L}$, the ionic strength of these solutions increased compared to those with TOC concentrations of $0.299 \mathrm{~mol} / \mathrm{L}$ (Tables 7 and 8). The ionic strength of the acetate-containing solution was greater than that of the other solutions, despite the larger number of formate ions per mole of TOC. (Formate contains one mole of carbon per formula unit, whereas acetate, glycolate, and oxalate contain 2, 3, and 2 moles of $C$ per formula unit, respectively). At the higher concentration of TOC, the total solids of the acetate, formate, glycolate, and oxalate solutions increased compared to those when TOC $=0.299 \mathrm{~mol} / \mathrm{L}$, primarily as a result of the formation of their respective Na-organic solids. Results of the glycolate solution simulation were calculated differently than the other systems presented in Table 8. Preliminary OLI simulations predicted that sodium glycolate would not precipitate from solution, a conclusion inconsistent with the solubility data presented in Table 6 and our experience with glycolate aqueous chemistry. To provide a somewhat better estimate, OLI was run in a manner to force it to precipitate $2.425 \mathrm{~mol} / \mathrm{L}$ sodium glycolate, the concentration of sodium acetate that OLI predicted would precipitate from solution. This analogue was selected because of its similar solubility (Table 6$)$ and concentration $(1.68 \mathrm{~mol} / \mathrm{L}$ acetate, $1.12 \mathrm{~mol} / \mathrm{L}$ glycolate). The calculated-glycolate suspension had approximately the same 
$\mathrm{pH}$ and ionic strength as the other solutions, but differed in that it contained lower concentration of solids. Glycolate was used in the plutonium separation process as a complexing agent. The lower calculated solids may in part be attributed to the fact that the glycolate existed primarily in the aqueous phase as complexed species. Additional attention will need to be directed at resolving the glycolate solid-phase thermodynamic data for future simulations. (Glycolate solubility data measured in high ionic strength solutions (part of this data is presented in Table 6, Barney 1996, 1997), is presently being entered into the OLI database.)

Table 8. pH, Ionic Strength, and Precipitates Formed in Simulated Envelope A When all the Carbon is Assigned to Acetate, Formate, Glycolate, and Oxalate (TOC $=3.36$ $\mathrm{mol} / \mathrm{L})^{(\mathrm{a})}$

\begin{tabular}{|c|c|c|c|c|c|}
\hline & & Acetate & Formate & Glycolate ${ }^{(a)}$ & Oxalate \\
\hline$\overline{\mathrm{pH}}$ & & 16.3 & 16.0 & 16.2 & 16.0 \\
\hline Ionic Strength & & 20.9 & 19.4 & 19.4 & 19.8 \\
\hline $\mathrm{NaF}$ & $\mathrm{mol} / \mathrm{L}$ & 0.017 & 0.016 & 0.030 & 0 \\
\hline $\mathrm{NaNO}_{3}$ & $\mathrm{~mol} / \mathrm{L}$ & 4.081 & 3.214 & 3.406 & 4.009 \\
\hline $\mathrm{Ca}(\mathrm{OH})_{2}$ & $\mathrm{~mol} / \mathrm{L}$ & 0.002 & 0.002 & 0.002 & 0 \\
\hline $\mathrm{KNO}_{3}$ & $\mathrm{~mol} / \mathrm{L}$ & 1.721 & 1.402 & 1.137 & 1.770 \\
\hline $\mathrm{Na}_{3} \mathrm{FSO}_{4}$ & $\mathrm{~mol} / \mathrm{L}$ & 0 & 0 & 0.009 & 0 \\
\hline $\mathrm{NaCl}$ & $\mathrm{mol} / \mathrm{L}$ & 0.159 & 0.028 & 0.073 & 0.030 \\
\hline $\mathrm{NaNO}_{2}$ & $\mathrm{~mol} / \mathrm{L}$ & 3.139 & 2.033 & 2.224 & 2.494 \\
\hline $\mathrm{NaACET}-3 \mathrm{H}_{2} \mathrm{O}$ & $\mathrm{mol} / \mathrm{L}$ & 2.425 & 0 & 0 & 0 \\
\hline $\mathrm{NaCOOH}$ & $\mathrm{mol} / \mathrm{L}$ & 0 & 5.318 & 0 & 0 \\
\hline Na-Glycolate & $\mathrm{mol} / \mathrm{L}$ & 0 & 0 & 2.425 & \\
\hline $\mathrm{Na}_{2} \mathrm{C}_{2} \mathrm{O}_{4}$ & $\mathrm{~mol} / \mathrm{L}$ & 0 & 0 & 0 & 3.608 \\
\hline Total solids & $\mathrm{mol} / \mathrm{L}$ & 11.544 & 12.013 & 9.306 & 11.910 \\
\hline
\end{tabular}

A series of simulations was conducted to evaluate the influence of varying the concentration of oxalate added to the simulated Envelope $A$ from 0 to $0.45 \mathrm{~mol} / \mathrm{L}$ (Figure 1). Oxalate has been used as a process chemical and is also a degradation product of the carboxylic acid based complexants that have been used at Hanford. While sodium oxalate has low solubility in high ionic strength LAW solutions, the dilute $(<1 \mathrm{M})$ washes of HLW pretreatment are predicted by OLI to be favorable to dissolution (Orme 1998). The end of the second wash washes most of the organic carbon out of the pretreated sludge. The results were as expected, oxalate concentrations in the aqueous and solid phases behaved as if they were saturated with respect to Na-oxalate, i.e., as more Naoxalate was added more $\mathrm{Na}$-oxalate was calculated as a solid. The $\mathrm{pH}$ remained largely constant at 16 and the ionic strength remained largely constant at 20 . Aqueous oxalate 
concentrations (primarily as the oxalate-free ion) did not increase in simulations receiving greater than $0.05 \mathrm{~mol} / \mathrm{L} \mathrm{Na}$-oxalate. The relative concentrations of sodium acetate and sodium formate precipitates in Table 8 are somewhat inconsistent with the laboratory solubility data presented in Table 6 . This suggests that some refinement of the solubility values used by OLI needs to be made prior to future calculations. Refinement could be accomplished by adjusting modeling parameters to better represent experimental results.

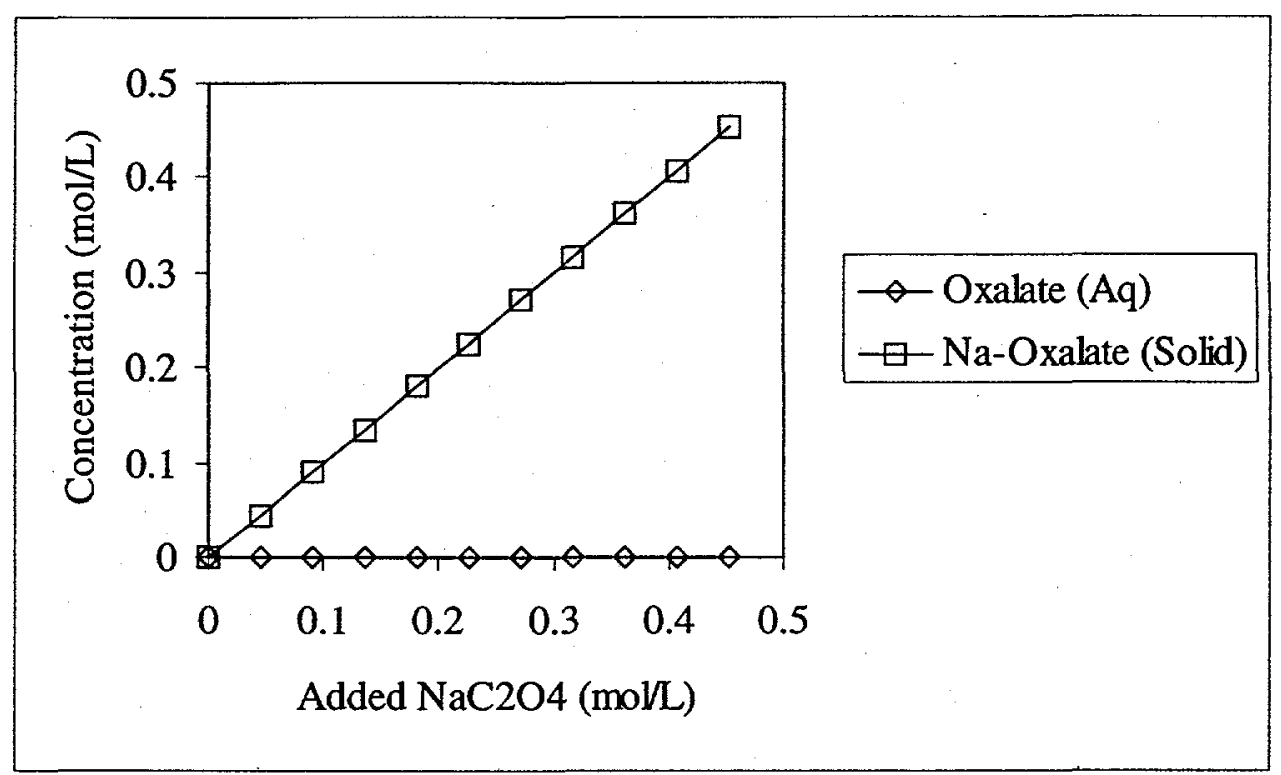

Figure 1. Oxalate activity in solid and aqueous phases vs. sodium-oxalate additions to simulated Envelope A. Oxalate (Aq) reflects the total concentration of oxalate in solution (primarily as the oxalate-free ion) and $\mathrm{Na}$-Oxalate (Solid) is the total concentration of oxalate in solids (primarily as $\mathrm{Na}$-oxalate).

\subsection{Acidity Issue}

\subsubsection{Titration of Envelope A with Nitric Acid}

There are several places in the process flowsheet where an acidic stream may be mixed into the feed stream. For example, the cleaning solution from the HLW ultrafiltration system will contain dilute nitric acid. Similarly, the HLW melter off-gas condensate may be acidic. Acidifying the feed stream may result in increased formation of solids that may in turn plug the cross flow filtration process and send more non-radioactive solids to high level waste glassification.

The influence of adding 0 to $7.75 \mathrm{~mol} / \mathrm{L}$ (or 0 to $30 \mathrm{~mol}$ ) of nitric acid $\left(\mathrm{HNO}_{3}\right.$ ) to Envelope A (Table 2; Tank 241-AW-101) was evaluated (Figures 3, 4, and 5). Envelope A was very well buffered between $\mathrm{pH} 16.2$ and 14.6 , requiring $4.6 \mathrm{~mol} / \mathrm{L}$ of $\mathrm{HNO}_{3}$ to decrease the $\mathrm{pH}$ by this much. Increasing the $\mathrm{HNO}_{3}$ concentration by an additional 1.3 
$\mathrm{mol} / \mathrm{L}\left(6 \mathrm{~mol} \mathrm{HNO}_{3}\right)$, decreased the $\mathrm{pH}$ another 11 units, from 14.6 to 3.6. This high buffering capacity of the feed in the high $\mathrm{pH}$ range is a valuable attribute for maintaining desired solutes in solution. As the amount of $\mathrm{HNO}_{3}$ added increased, the ionic strength of the solutions gradually decreased. This latter trend is consistent with the notion that as more solids are formed in increasingly acidic solutions, less solutes remain in solution.

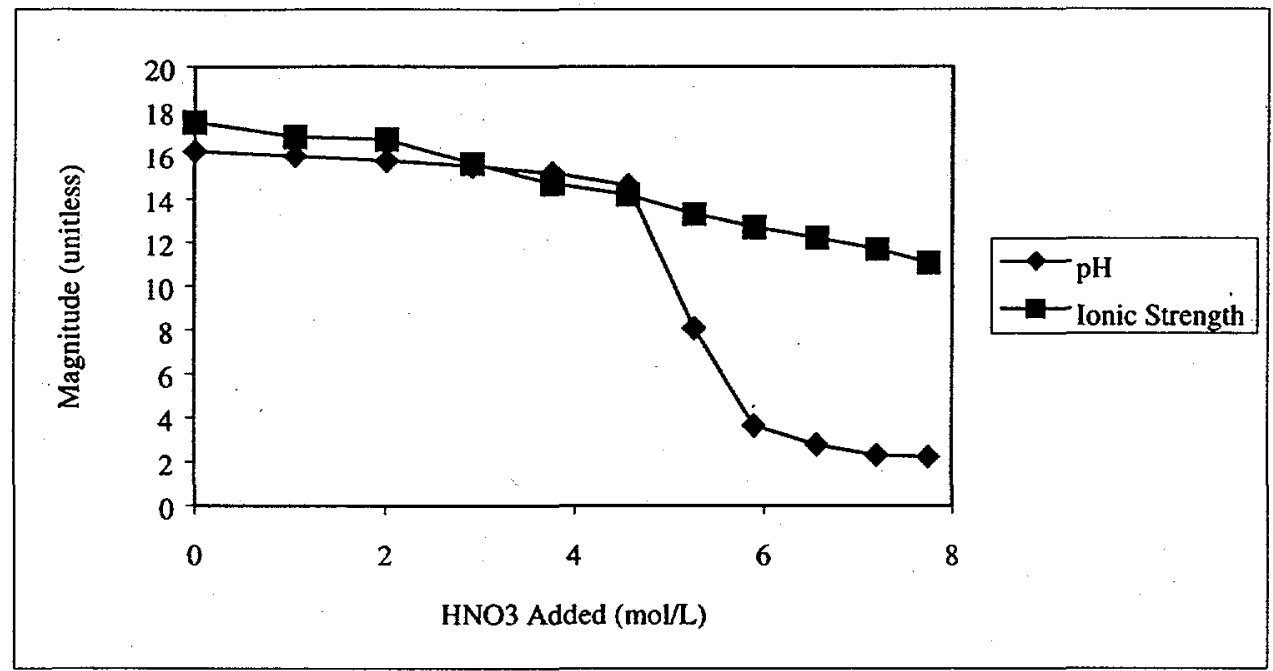

Figure 2. Effect of Adding $\mathrm{HNO}_{3}$ to the $\mathrm{pH}$ and Ionic Strength of Envelope $\mathrm{A}$ (TOC= $0.299 \mathrm{~mol} / \mathrm{L}$ and all the TOC was Assumed to be Acetate)

Increases in $\mathrm{HNO}_{3}$ additions resulted in increases in the formation of solids (Figure 3). At $\mathrm{pH} 16.2$, when no $\mathrm{HNO}_{3}$ was added in the simulation, there was a total of $6.0 \mathrm{~mol} / \mathrm{L}$ of insoluble solids. This constitutes about a third of the total molar concentration in the suspension. As mentioned earlier, it is likely that OLI over estimates the actual amount of precipitation that will actually exist for a number of reasons, including that the actual system may not come to complete equilibrium. When $7.75 \mathrm{HNO}_{3} \mathrm{~mol} / \mathrm{L}$ was added, the solution $\mathrm{pH}$ decreased to 2.25 and the amount of solids formed increased to $7.8 \mathrm{~mol} / \mathrm{L}$, an increase of $30 \%$. Interestingly, as the $\mathrm{pH}$ dropped from 16.2 to 14.6 , the total insoluble solids formed increased from 6.0 to $6.5 \mathrm{~mol} / \mathrm{L}$, an increase of $8 \%$. Not surprisingly, sodium solids were the dominant solids formed in all simulations; followed by potassium solids in higher $\mathrm{pH}$ systems and aluminum solids at lower $\mathrm{pH}$ systems. Calcium solids never exceeded $0.1 \mathrm{~mol} / \mathrm{L}$, irrespective of the amount of $\mathrm{HNO}_{3}$ added. 


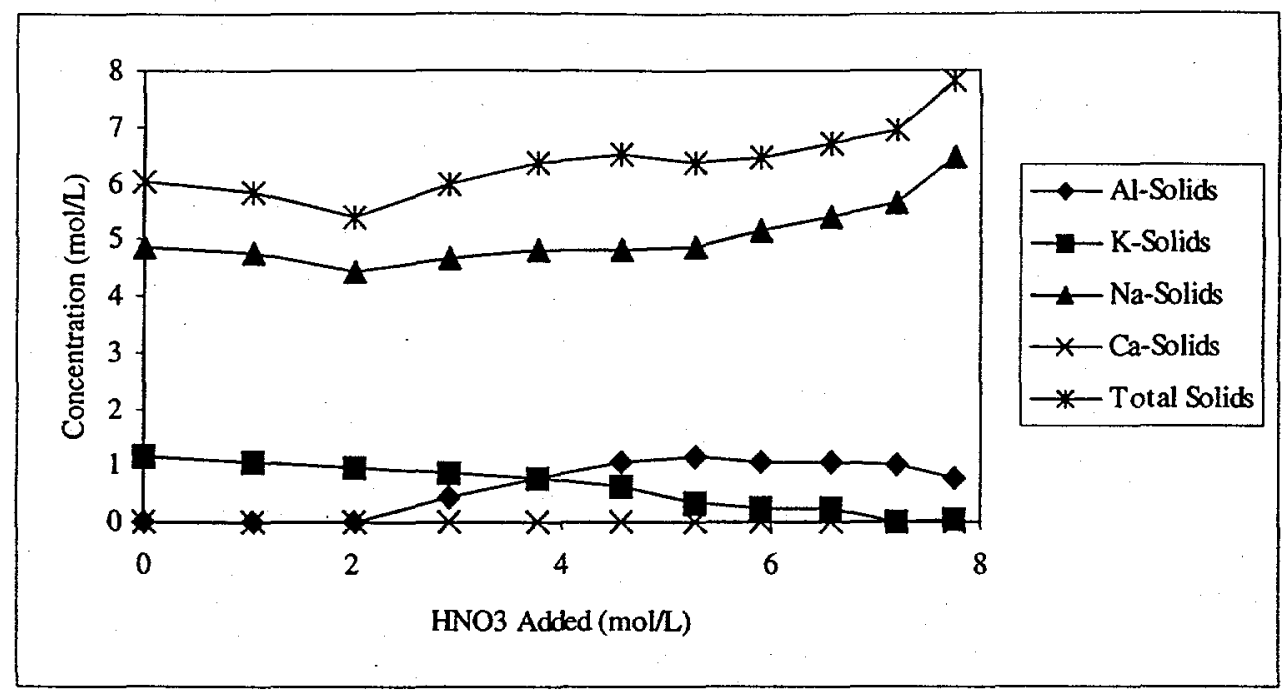

Figure 3. Effect of Adding $\mathrm{HNO}_{3}$ to Envelope $\mathrm{A}$ on the Formation of Solids (TOC = $0.299 \mathrm{~mol} / \mathrm{L}$ and all the TOC was Assumed to be Acetate)

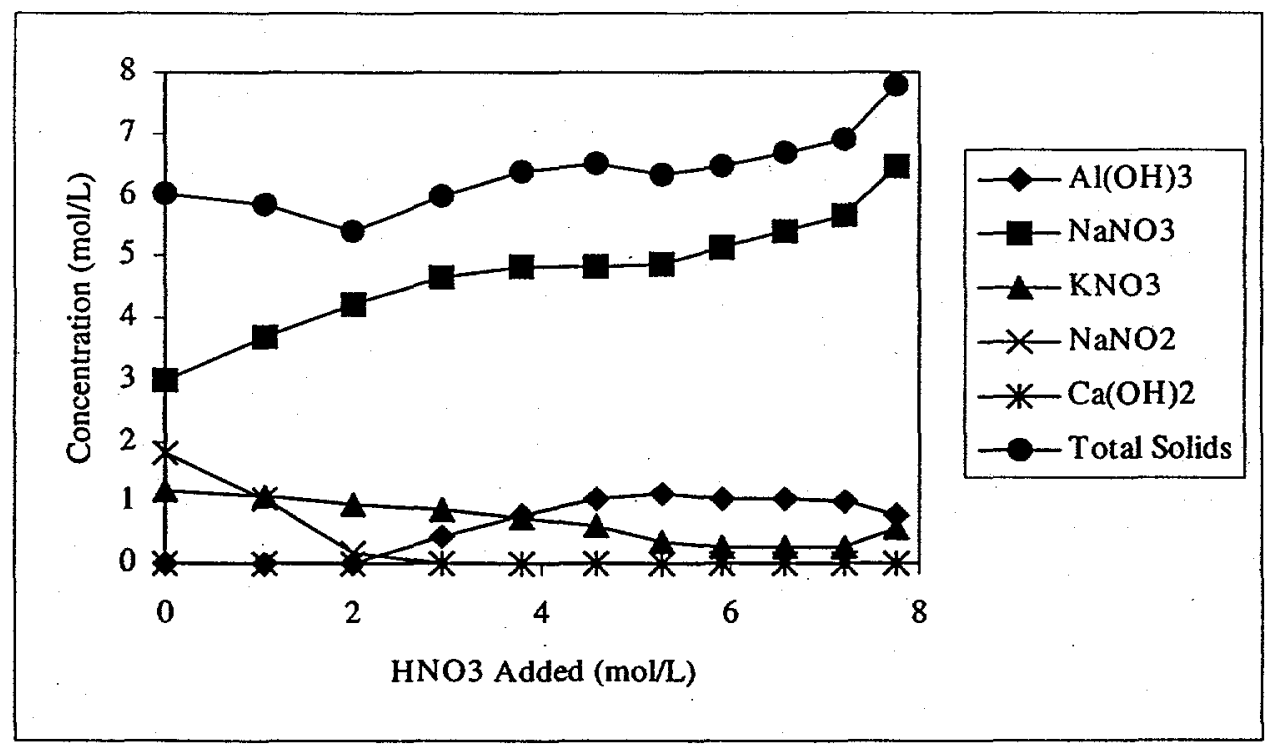

Figure 4. Effect of Adding $\mathrm{HNO}_{3}$ to Envelope $\mathrm{A}$ on the Formation of Selected Dominant Solids (TOC $=0.299 \mathrm{~mol} / \mathrm{L}$ and all the TOC was Assumed to be Acetate)

The dominant precipitates predicted to form during these simulations are presented in Figure 4. The dominant sodium salt $\mathrm{NaNO}_{3}$, with appreciably less $\mathrm{NaNO}_{2}$ also being present. As more $\mathrm{HNO}_{3}$ was added to the system, the proportion of $\mathrm{NaNO}_{3}$ in the system 
increased. The dominant potassium solid was predicted to be $\mathrm{KNO}_{3}$. The dominant aluminum precipitate was predicted to be $\mathrm{Al}(\mathrm{OH})_{3}$ (gibbsite).

It was anticipated that aluminum precipitation would be especially important as the $\mathrm{pH}$ of the waste stream decreased. No aluminum solids were formed in solutions that received less than $2 \mathrm{~mol} / \mathrm{L} \mathrm{HNO}_{3}$, or less than $\mathrm{pH}$ 15.7. Precipitation of $\mathrm{Al}(\mathrm{OH})_{3}$ began below $\mathrm{pH}$ 15.7 and remained constant at $\mathrm{HNO}_{3}$ additions $>4.56 \mathrm{~mol} / \mathrm{L} \mathrm{HNO}_{3}$, or $\mathrm{pH} 14.6$. Aqueous aluminum chemistry followed expected trends. The aluminum species in a low-, high-, and mid-pH solutions are presented in Table 8. In the two lower $\mathrm{pH}$ solutions, fluoride species dominated the aqueous aluminum chemistry. In the $\mathrm{pH} 16.2$ solution, essentially all the aluminum was predicted to be as tetrahydroxyaluminate anion, $\mathrm{Al}(\mathrm{OH})_{4}{ }^{-}$.

Table 8. Aluminum Aqueous Speciation of Three Solutions in the $\mathrm{HNO}_{3}$ Titration of Envelope A (TOC $=0.299 \mathrm{~mol} / \mathrm{L}$ and all the TOC was Assumed to be Acetate)

\begin{tabular}{lccc}
\hline $\mathrm{pH}$ & $\begin{array}{c}2.3^{(\mathrm{a})} \\
(\mathrm{mol} / \mathrm{L})\end{array}$ & $\begin{array}{c}8.1 \\
(\mathrm{~mol} / \mathrm{L})\end{array}$ & $\begin{array}{c}16.2 \\
(\mathrm{~mol} / \mathrm{L})\end{array}$ \\
\hline $\mathrm{AlF}_{3}{ }^{0}$ & $0^{(6)}$ & $9.65 \mathrm{E}-07$ & 0 \\
$\mathrm{Al}(\mathrm{OH})_{3}{ }^{0}$ & $5.05 \mathrm{E}-10$ & $4.39 \mathrm{E}-10$ & $1.99 \mathrm{E}-11$ \\
$\mathrm{AlF}_{4}{ }^{-}$ & 0 & $2.81 \mathrm{E}-05$ & 0 \\
$\mathrm{ALF}_{5}$ & 0 & $1.63 \mathrm{E}-04$ & 0 \\
$\mathrm{AlF}_{6}{ }^{2-}$ & 0 & $8.63 \mathrm{E}-04$ & 0 \\
$\mathrm{AlF}^{2+}$ & $3.03 \mathrm{E}-02$ & $8.45 \mathrm{E}-11$ & 0 \\
$\mathrm{Al}^{3+}$ & 0.209 & 0 & 0 \\
$\mathrm{Al}^{-}(\mathrm{OH})_{2}{ }^{+}$ & $1.58 \mathrm{E}-06$ & $3.22 \mathrm{E}-12$ & 0 \\
$\mathrm{Al}(\mathrm{OH})_{4}^{-}$ & 0 & $3.36 \mathrm{E}-08$ & 1.45 \\
$\mathrm{AlOH}{ }^{2+}$ & $9.01 \mathrm{E}-04$ & 0 & 0 \\
$\left.\mathrm{Al}(\mathrm{SO})_{4}\right)^{-}$ & $4.86 \mathrm{E}-07$ & 0 & 0 \\
$\mathrm{AlSO}{ }_{4}{ }^{-}$ & $3.73 \mathrm{E}-05$ & 0 & 0 \\
$\mathrm{TOTAL} \mathrm{Aq.}^{-}$ & 0.240 & $1.06 \mathrm{E}-03$ & 1.45 \\
\hline
\end{tabular}

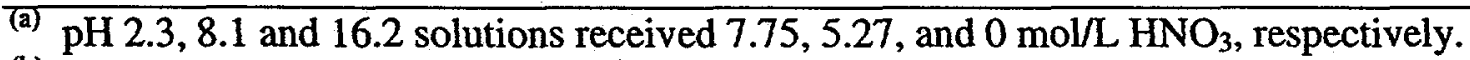

(b) Species concentrations $<1 \mathrm{E}-12 \mathrm{~mol} / \mathrm{L}$ are reported as $0 \mathrm{~mol} / \mathrm{L}$ for ease in reading.

The solubility of aluminum in the $\mathrm{H}_{2} \mathrm{O}-\mathrm{Al}_{2} \mathrm{O}_{3}-\mathrm{Na}_{2} \mathrm{O}$ system has been documented (Orme 1998). Using triangular solution field diagrams Orme (1998) calculated that solid phases in this system could be largely avoided only with solutions containing more than $60 \%$ water and less than $20 \% \mathrm{Al}_{2} \mathrm{O}_{3}$, and only then if an appropriate amount of $\mathrm{Na}_{2} \mathrm{O}$ is present. Temperature variations between 30 and $95^{\circ} \mathrm{C}$ did not have dramatic effects on calculated phase diagrams.

Under some conditions, increasing the water content of an aluminum-bearing liquid may precipitate gibbsite $\left[\mathrm{Al}(\mathrm{OH})_{3}\right]$. Introduction of acids, including $\mathrm{CO}_{2}$ from the air, may 
have a similar effect. For waste that has precipitated gibbsite, an addition of $\mathrm{Na}_{2} \mathrm{O}$ (as caustic) may be sufficient to resolubilize the gibbsite (Herting et al. 1986).

Sterner et al. (1996) determined using Raman spectroscopy that the soluble aluminum species present in the Hanford tank is $\mathrm{Al}(\mathrm{OH})_{4}$. The tetrahydroxyaluminate anion, $\mathrm{Al}(\mathrm{OH})_{4}{ }^{-}$, may be in equilibrium with the solid gibbsite phase or solid sodium aluminate $\left(\mathrm{NaAlO}_{2}\right)$ phase, depending on the hydroxide concentration and the overall ionic strength.

\subsubsection{Mixing of an Off-Gas Condensate Stream with Envelope A}

Mixing the off-gas condensate stream with the feed stream is an example where "acidification" of the feed stream can occur, i.e., lowering the $\mathrm{pH}$. This was identified in the Test Specification Plan as Item 6 (Stream 91, Melter Off Gas Stream and Envelope A, Colebrook and Coleman 1998a, 1998b). Using OLI, Stream 91 (Table 9) and Envelope A (Table 2) were mixed to create final suspensions containing $0,6,28,54,78,96$, and $100 \%$ (v) Envelope A (Appendix D). 
Table 9. Chemical Composition of Off-Gas Condensate Stream (Stream 91, Colebrook and Coleman 1998a, 1998b)

\begin{tabular}{|c|c|c|c|}
\hline Component & $\begin{array}{l}\text { Mass } \\
(\mathrm{Mt} / \mathrm{d})\end{array}$ & $\begin{array}{l}\text { Concentration } \\
(\mathrm{mol} / \mathrm{L})\end{array}$ & Comment $^{(a)}$ \\
\hline $\mathrm{Al}$ & 0.01173 & 0.01403 & \\
\hline $\mathrm{Ba}$ & $1.1 \mathrm{E}-07$ & $2.5 \mathrm{E}-08$ & 1 \\
\hline $\mathrm{Ca}$ & 0.00463 & 0.00373 & 2 \\
\hline $\mathrm{Cd}$ & 7.7E-06 & $2.2 \mathrm{E}-06$ & 1,2 \\
\hline $\mathrm{Cl}$ & 0.106 & 0.09652 & \\
\hline $\mathrm{Cr}$ & 0.00025 & 0.00015 & 2 \\
\hline $\mathrm{F}$ & 0.01109 & 0.01884 & \\
\hline $\mathrm{Fe}$ & 0.0126 & 0.00728 & 2 \\
\hline $\mathrm{Hg}$ & 0.00058 & $9.3 \mathrm{E}-05$ & 1 \\
\hline $\mathbf{K}$ & 0.08575 & 0.0708 & 2 \\
\hline $\mathrm{Ni}$ & $2.4 \mathrm{E}-06$ & $1.3 \mathrm{E}-06$ & 1,2 \\
\hline $\mathrm{NO}_{2}$ & 0 & 0 & 1 \\
\hline $\mathrm{NO}_{3}$ & 0.459 & 0.23898 & \\
\hline $\mathrm{OH}$ & 0 & 0 & 1 \\
\hline $\mathrm{Pb}$ & 0.00014 & $2.2 \mathrm{E}-05$ & 1 \\
\hline $\mathrm{PO}_{4}$ & 0 & 0 & 1,2 \\
\hline $\mathrm{SO}_{4}$ & $2.8 \mathrm{E}-05$ & $9.4 \mathrm{E}-06$ & \\
\hline TOC & 0 & 0 & 1 \\
\hline $\mathrm{U}$ & $1.4 \mathrm{E}-05$ & $1.9 \mathrm{E}-06$ & 1 \\
\hline $\mathrm{Na}$ & 0.494 & 0.69365 & 2 \\
\hline Cs & $4.9 \mathrm{E}-08$ & 1.2E-08 & 1 \\
\hline $\mathrm{Sr}$ & $7.4 \mathrm{E}-09$ & $2.6 \mathrm{E}-09$ & 1 \\
\hline $\mathrm{NH}_{3}$ & 0 & 0 & 1 \\
\hline $\mathrm{Am}$ & $1.6 \mathrm{E}-10$ & $2.1 \mathrm{E}-11$ & 1 \\
\hline $\mathrm{Pu}$ & $1.6 \mathrm{E}-10$ & $2.2 \mathrm{E}-11$ & 1 \\
\hline $\mathrm{Si}$ & 0.05273 & 0.06061 & 2 \\
\hline $\mathrm{B}$ & 0.04375 & 0.13066 & 2 \\
\hline
\end{tabular}

(a) Comments:

1. Dropped constituents with low concentrations or concentrations equal to zero $\mathrm{mol} / \mathrm{L}$ because OLI has a limited number of constituents that it can tract during a simulation.

2. Ferrara et al (1998) measured the chemical composition of off-gas condensate formed during experimental vitrification of Envelope A (Tank AW-101; originally described in Nash 1997). The vitrification and off-gas condensate collection processes (dry-ice cold trap) used by Ferrara et al. did not mimic expected plant conditions or the conditions simulated by Colebrook and Coleman $(1998 \mathrm{a}, 1998 \mathrm{~b})$. Thus, their experimental results are not expected to be identical to those of Colebrook and Coleman. Ferrara et al (1998) reported the following concentration, in units of $\mathrm{mol} / \mathrm{L}: \mathrm{B}=6.0 \mathrm{e}-5, \mathrm{Ca}=1.4 \mathrm{e}-5, \mathrm{Cd}=1.8 \mathrm{e}-7, \mathrm{Cr}=3.5 \mathrm{e}-5, \mathrm{Fe}=2.9 \mathrm{e}-6, \mathrm{~K}=2.7 \mathrm{e}-4$, $\mathrm{Na}=1.8 \mathrm{e}-3, \mathrm{Ni}=1.7 \mathrm{e}-6, \mathrm{P}=7.7 \mathrm{e}-6, \mathrm{Si}=1.4 \mathrm{e}-4$, and $\mathrm{Zn}=7.2 \mathrm{e}-7$. 
Ferrara et al. (1998) measured the chemical composition of off gas condensate formed during small scale vitrification of Envelope A waste (Tank AW-101; originally described in Nash 1997). The vitrification and off-gas condensate collection processes (dry-ice cold trap) used by Ferrara et al. did not mimic expected plant conditions or the conditions simulated by Colebrook and Coleman (1998a, 1998b). Thus, their experimental results are not expected to be identical to those of Colebrook and Coleman (1998a). A full suite of chemical analyses of the off-gas condensate was not possible due to an insufficient sample volume. Analytical results from ICP-ES are presented in Table 9. Colebrook and Coleman (1998a) overestimated experimentally derived values in all cases, except for phosphate and nickel. Boron and Fe were overestimated by 3 to 4 orders of magnitude, whereas $\mathrm{Ca}, \mathrm{Cd}, \mathrm{Cr}, \mathrm{K}, \mathrm{Na}$, and $\mathrm{Si}$ were overestimated by 1 or 2 orders of magnitude.

As the proportion of the off-gas condensate stream increased in the mixture, the $\mathrm{pH}$ and ionic strength decreased (Figure 5). The $\mathrm{pH}$ decreased from 16.2 in $100 \%$ Envelope $A$ to $\mathrm{pH} 11.5$ in $100 \%$ of the off-gas condensate stream. Similarly, the ionic strength decreased from 17.4 in $100 \%$ Envelope $A$ to 0.8 in $100 \%$ of the off-gas condensate stream. Thus, the acidity issue as well as the dilution issue is introduced when these streams are mixed.

Total solids concentrations did not increase as the proportion of the off-gas condensate stream increased (Figure 6). The cause for the lack of solids formation upon the introduction of the acidic stream may be attributed in part to the fact that as the $\mathrm{pH}$ decreased, the ionic strength also decreased. The dominant precipitates formed were $\mathrm{KNO}_{3}$ and $\mathrm{NaNO}_{2}$ (Figure 6) when Envelope $\mathrm{A}$ accounted for the majority of the mixture, and $\mathrm{Al}(\mathrm{OH})_{3}$ and $\mathrm{Fe}(\mathrm{OH})_{3}$ (Figure 7) when the off-gas condensate stream accounted for the majority of the mixture. Additional details of the results of these simulations are presented in Appendix D.

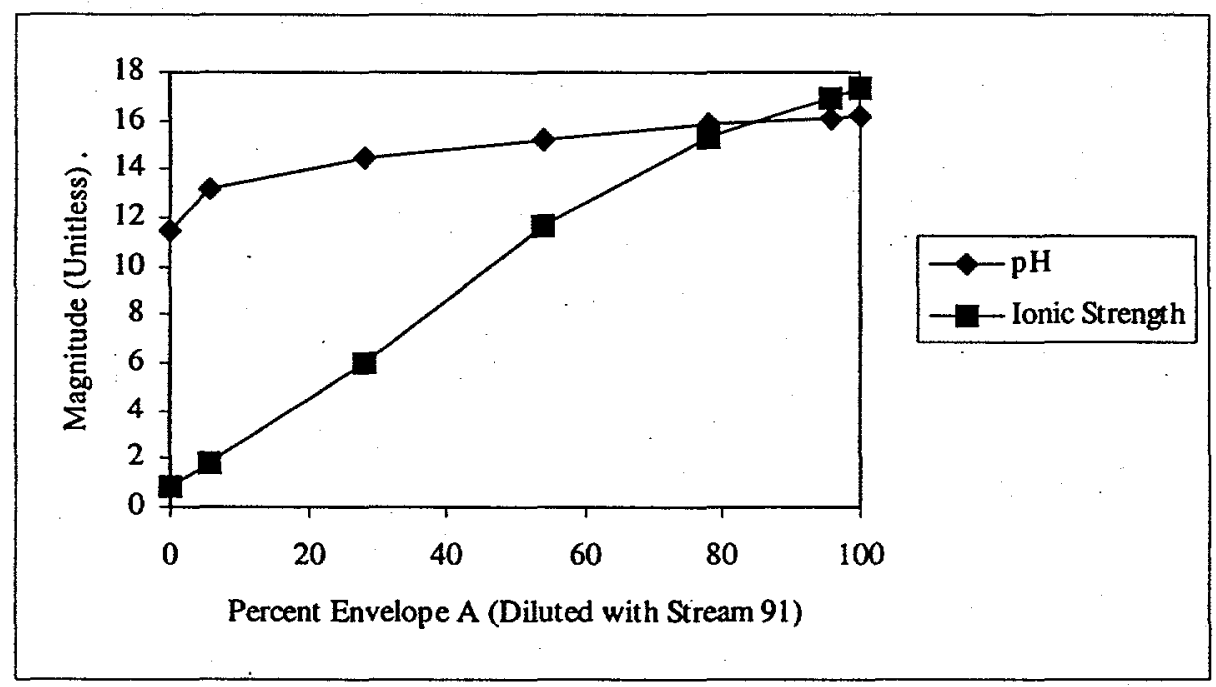

Figure 5. Effect of Mixing an Off-Gas Condensate Stream (Stream 91) with Envelope A on $\mathrm{pH}$ and Ionic Strength 


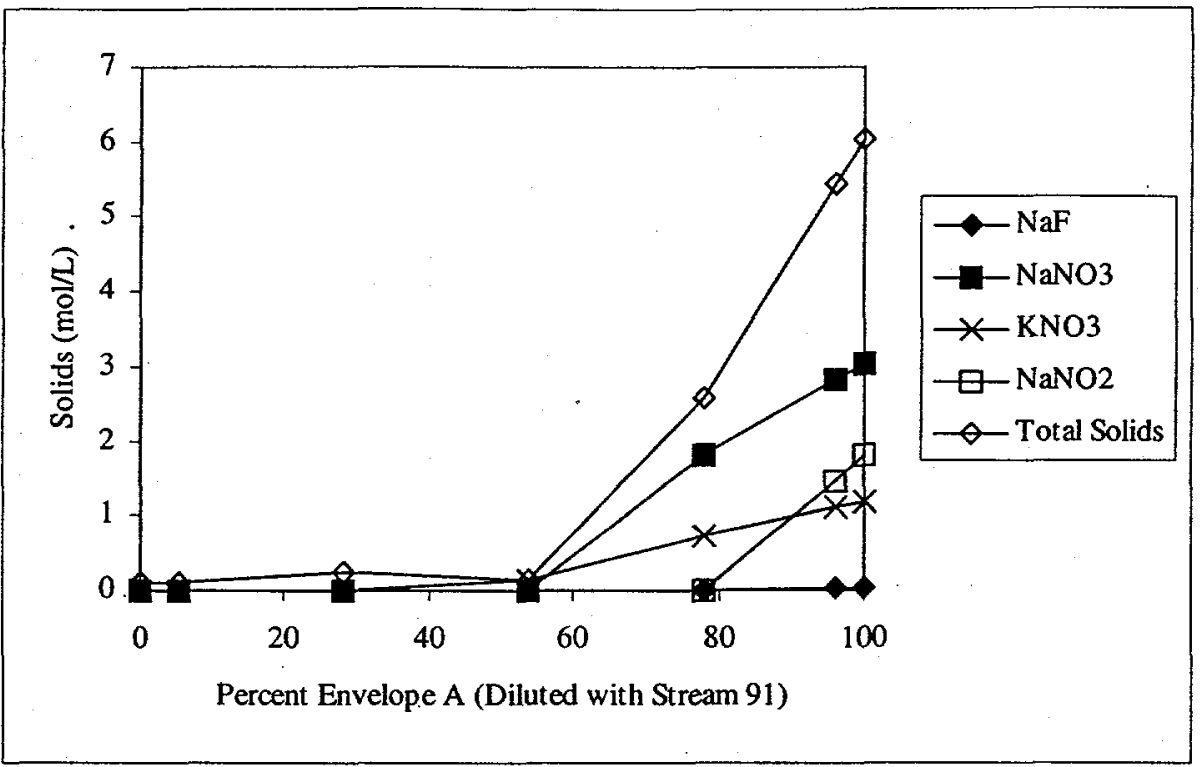

Figure 6. Effect of Mixing an Off-Gas Condensate Stream (Stream 91) with Envelope A on the Formation of Some Dominant Precipitates

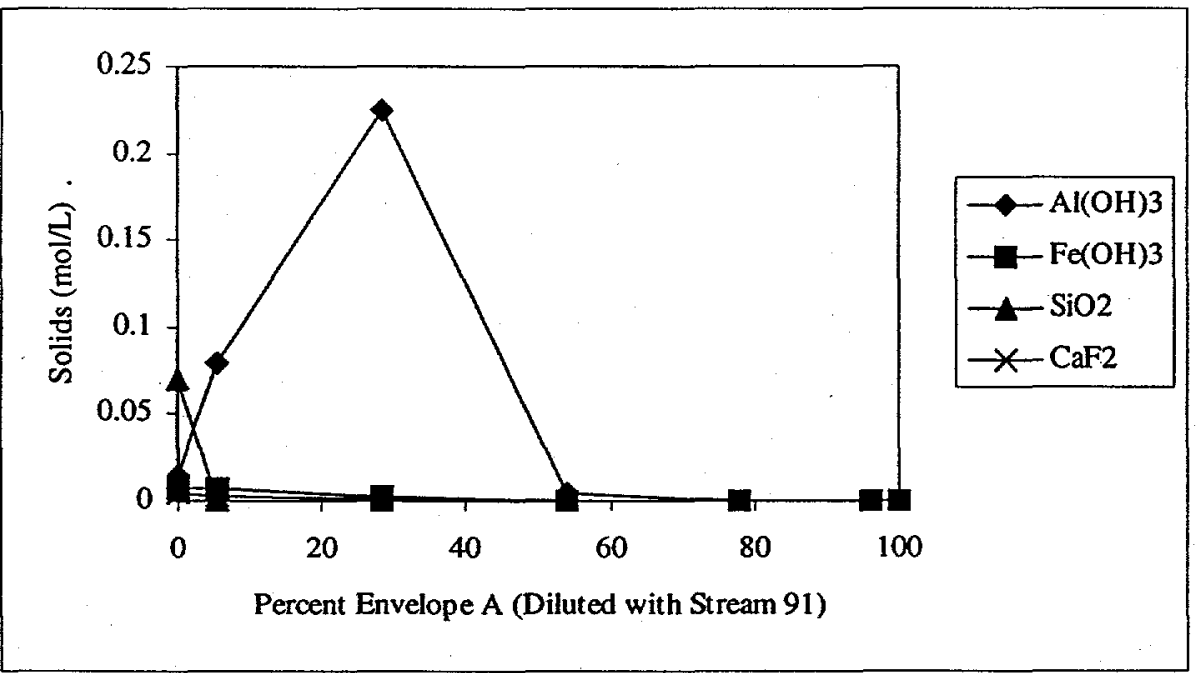

Figure 7. Effect of Mixing an Off-Gas Condensate Stream (Stream 91 with Envelope A on Formation of Selected Low-Concentration Precipitates 


\subsection{Heel Issue}

The Heel Issue is primarily concerned with the effect of mixing the heel of Envelope $C$ (e.g. Tank 241-AN-107) with Envelopes A (e.g., Tank 241-AW-101)or B (e.g., Tank 241-AZ-101) feed, as well as mixing of heels of $A$ and $B$. One of the postulated adverse effects of mixing any tank heels is that pertechnetate (in A or B) conversion to a nonexchangeable form of technetium, thereby decrease the efficiency of the technetium exchange column. Simulations were conducted to evaluate the effect of mixing varying ratios of Envelope A (Table 2) and Envelope C (Table 4) on the formation of solids. The technetium speciation problem will need to be addressed once laboratory experiments have been completed to further elucidate potential reactions involved in converting the pertechnetate into a non-exchangeable form. It is anticipated that a heel of up to $20 \mathrm{~m}^{3}$ ( $\sim 0.5 \mathrm{~m}$ above the RFD outlet) could be present in the LAW feed receipt vessel, which has a total capacity of $227 \mathrm{~m}^{3}$. Thus, the ratio of heel to new feed is $\sim 1: 10$. The calculations were performed at mixing ratios of $100,92,90,81,63,46$, and $0 \%(v)$ Envelope A.

The effect of mixing Envelopes $\mathrm{A}$ and $\mathrm{C}$ on suspension $\mathrm{pH}$ and ionic strength are presented in Figure 8. Envelope A (100\% Envelope A) has a lower ionic strength and a higher $\mathrm{pH}$ than Envelope $\mathrm{C}(0 \%$ Envelope $\mathrm{A}$ ). The $\mathrm{pH}$ of Envelope $\mathrm{C}$ was 10.4. This $\mathrm{pH}$ is too close to the lower limit permitted for the waste stream, i.e., $\mathrm{pH} 10$, and therefore, will likely be increased by the addition of caustic. The $\mathrm{pH}$ of the mixtures declined by only $0.4 \mathrm{pH}$ units as the proportion of Envelope A in the mixture decreased to $44 \%$. The next incremental increase in the proportion of Envelope $\mathrm{C}$ was $100 \%$ Envelope $\mathrm{C}$, with $\mathrm{pH} 10.4$.

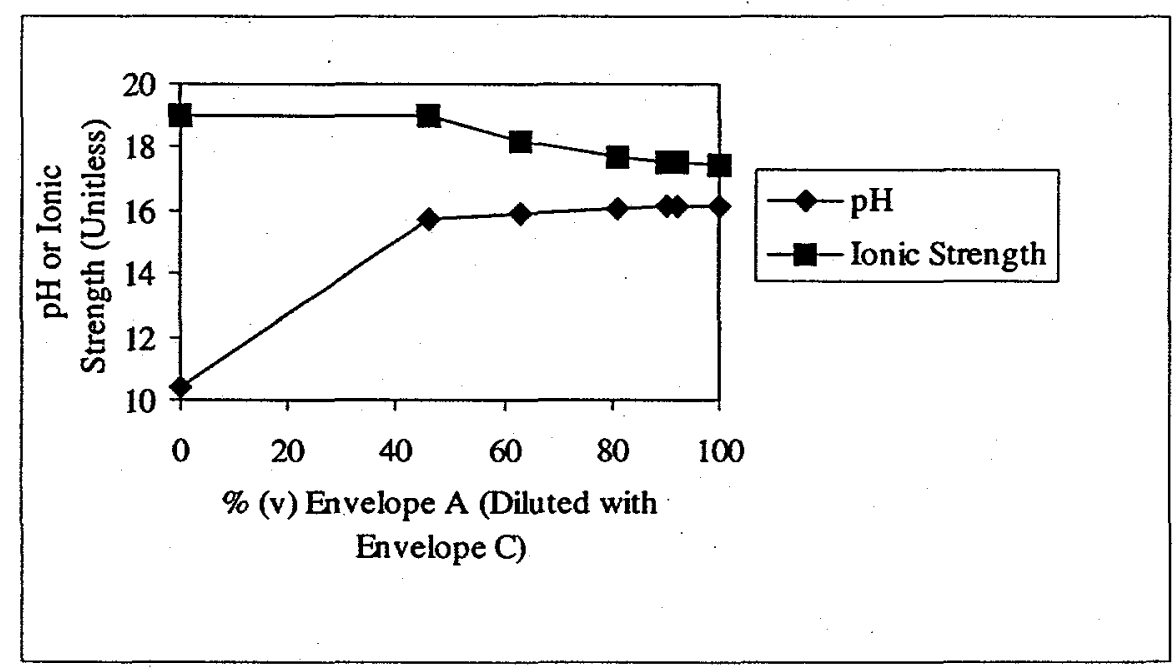

Figure 8. Effect of Mixing Envelopes A and C on Suspension $\mathrm{pH}$ and Ionic Strength

The quantity of total solids formed did not change greatly in the various combinations of Envelopes $A$ and $C$ (Figure 9). However, the types of solids formed did vary as a function of the ratios. Greater proportions of Envelope $\mathrm{A}$ in a mixture yielded greater the 
concentrations of $\mathrm{NaNO}_{2}$ and $\mathrm{KNO}_{3}$, and lower concentrations of $\mathrm{NaNO}_{3}$ and $\mathrm{Na}$-formate $(\mathrm{NaCOOH})$. It is important to keep in mind that the glycolate solids that would likely be formed as a result of introducing the glycolate in Envelope $\mathrm{C}$, are not presented in Figure 9 because of the absence of the appropriate constants in OLI. The staff at OLI Systems, Inc is presently developing and incorporating these constants into the OLI Public database. Additional detailed results from these heel-issue simulations are presented in Appendix B.

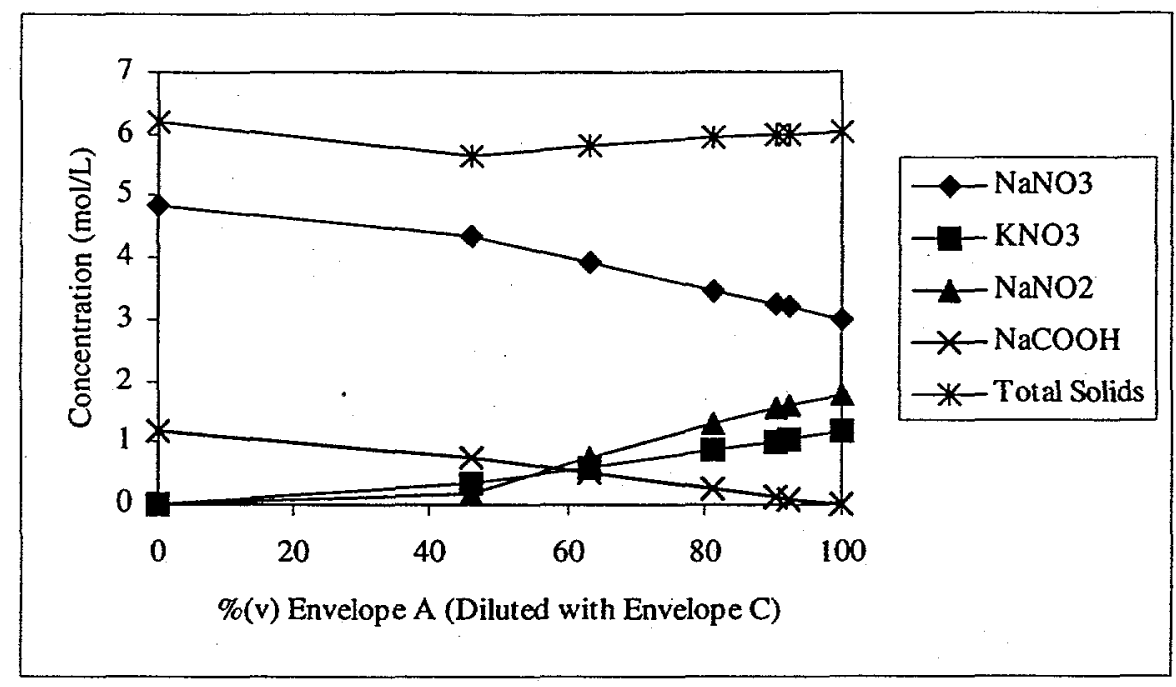

Figure 9. Effect of Mixing Envelopes A and C on Solids Formation

\subsection{Dilution Issue}

The dilution issue is concerned with the effect of diluting a waste stream, whereby the mixture chemistry changes in a manner that solids precipitate from solution. It is possible that by diluting a waste stream that the concentration of hydroxides would be decreased, thereby decreasing the $\mathrm{pH}$, and inducing precipitation. There are at least two locations in the proposed treatment process where this may occur. The first is where the water wash of Envelope D (HLW) is returned to Envelopes A, B, or C. This is Stream 20 in Colebrook and Coleman (1998a, 1998b) and is described as Item 2 in the Test Specifications of this task (Johnson 1999). The second location where dilution may occur is where the wash water from the LAW feed filtration is returned to Envelopes A, B, or C. This is Stream 43 in Colebrook and Coleman (1998a, 1998b) and is described as Item 7 in the Test Specifications of this task (Johnson 1999).

The effect of diluting Envelope A (Table 2) with Stream 20 was evaluated. Stream 20 is filtered permeate generated from the dewatering process of the HLW feed and its chemical composition was taken from Colebrook and Coleman (1998a, 1998b) (Table 10). 
Table 10. Stream 20 Chemical Composition Used in OLI Simulation: Permeate from HLW Feed Dewatering to LAW Treatment

\begin{tabular}{|c|c|c|c|}
\hline Component & Mass (Mt/d) ${ }^{(a)}$ & $\begin{array}{c}\text { Concentration } \\
(\mathrm{mol} / \mathrm{L})\end{array}$ & Comment $^{(b)}$ \\
\hline $\mathrm{Al}$ & $3.1 \mathrm{E}-07$ & $3.4 \mathrm{E}-07$ & 1 \\
\hline $\mathrm{Ba}$ & $3 \mathrm{E}-06$ & $6.2 \mathrm{E}-07$ & 1 \\
\hline $\mathrm{Ca}$ & 3.4E-05 & $2.4 \mathrm{E}-05$ & \\
\hline $\mathrm{Cd}$ & $6.5 \mathrm{E}-06$ & $1.7 \mathrm{E}-06$ & \\
\hline $\mathrm{Cl}$ & 0.0014 & 0.00114 & \\
\hline $\mathrm{Cr}$ & $3.8 \mathrm{E}-05$ & $2.1 \mathrm{E}-05$ & 2 \\
\hline $\mathrm{F}$ & 0.00029 & 0.00044 & \\
\hline $\mathrm{Fe}$ & $6.9 \mathrm{E}-07$ & $3.5 \mathrm{E}-07$ & 1 \\
\hline $\mathrm{Hg}$ & 0 & 0 & 1 \\
\hline $\mathrm{K}$ & 0.00019 & 0.00014 & \\
\hline $\mathrm{La}$ & $8.3 \mathrm{E}-08$ & $1.7 \mathrm{E}-08$ & 1 \\
\hline $\mathrm{Ni}$ & $2.1 \mathrm{E}-05$ & $1 \mathrm{E}-05$ & 1 \\
\hline $\mathrm{NO}_{2}$ & 0.00213 & 0.00134 & \\
\hline $\mathrm{NO}_{3}$ & 0.03899 & 0.01813 & \\
\hline $\mathrm{OH}$ & 0.02697 & 0.04575 & \\
\hline $\mathrm{Pb}$ & $2.7 \mathrm{E}-05$ & $3.7 \mathrm{E}-06$ & \\
\hline $\mathrm{PO}_{4}$ & 0.00103 & 0.00031 & \\
\hline $\mathrm{SO}_{4}$ & 0.00102 & 0.00031 & \\
\hline TIC & 0 & 0 & 1 \\
\hline TOC & 0.00318 & 0.00764 & 3 \\
\hline $\mathrm{U}$ & 0.00079 & $9.5 \mathrm{E}-05$ & 2 \\
\hline $\mathrm{Na}$ & 0.03596 & 0.04511 & \\
\hline Cs & 7.5E-05 & $1.6 \mathrm{E}-05$ & \\
\hline $\mathrm{Sr}$ & $1.2 \mathrm{E}-07$ & $3.9 \mathrm{E}-08$ & 1 \\
\hline $\mathrm{NH}_{3}$ & 0 & 0 & 1 \\
\hline Formate & NA & 0.00764 & 3 \\
\hline
\end{tabular}

(a) Values reported by Colebrook and Coleman 1998a.

(b) Comments:

1. Dropped constituent because of its low concentrations.

2. Dropped constituent because of its low concentrations and its presence in the simulation require OLI to form a large number of aqueous salts. OLI can track only 50 salts during the PROCESS CHEMISTRY step of the simulations.

3. OLI does not recognize TOC as a constituent. Consequently, all carbon in the stream was assumed to exist in the form of formate. 
The $\mathrm{pH}$ of the mixed suspensions never decreased below that of the dilute stream, $\mathrm{pH}$ 12.6 (Figure 10). Based on the results of the $\mathrm{HNO}_{3}$ titration simulations (Figure 4) and the mixture of the acidic stream, Stream 91, with Envelope A (Figure 9), pH 12.6 is sufficiently high to maintain solutes in solution. The ionic strength of the mixture decreased linearly with the proportion of Stream 20 in the mixture (Figure 10). In mixtures containing more than 8 to $46 \%$ (v) Stream 20, essentially no precipitation occurred (Figure 11). This is qualitatively consistent with observations made of a different Envelope A sample collected from Tank AN-103 that was diluted by about 50\% with $0.01 \mathrm{M} \mathrm{NaOH}$ (personal communications with Michael Hay, WSRC). Undiluted Envelope A (Tank AN-103) sample consisted of $~ 50 \%$ (v) solids. Upon dilution with $0.01 \mathrm{M} \mathrm{NaOH}$, solids accounted for $<1 \%$ (v) of the sample.

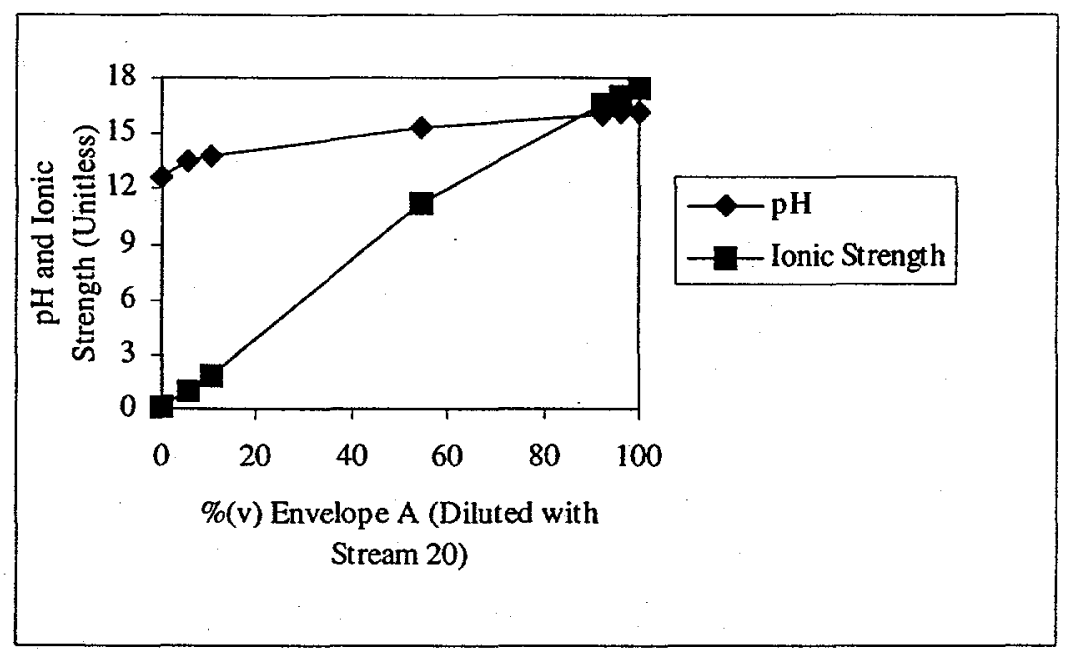

Figure 10. Effect of Mixing a Dilute Stream (Stream 20) with Envelope A on pH and Ionic Strength

Closer examination of the low concentration of precipitates formed in highly dilute Envelope A mixtures shows the importance of $\mathrm{Al}(\mathrm{OH})_{3}$ (gibbsite) precipitates (Appendix C). Essentially no precipitates existed in pure Stream 20 . In 6, 10, and 54\% Envelope A mixtures, $0.056,0.10$, and $0.016 \mathrm{~mol} / \mathrm{L} \mathrm{Al}(\mathrm{OH})_{3}$ were formed, respectively. These $\mathrm{Al}(\mathrm{OH})_{3}$ concentrations account for $100 \%, 100 \%$, and $20 \%$, respectively, of the total solids formed in these solutions. Thus, although very low concentrations of precipitates formed in these dilute mixtures, they were no longer dominated by sodium solids, they were dominated by aluminum solids. This result has significant implications for filtration of this solution and the fate of the insoluble solids. 


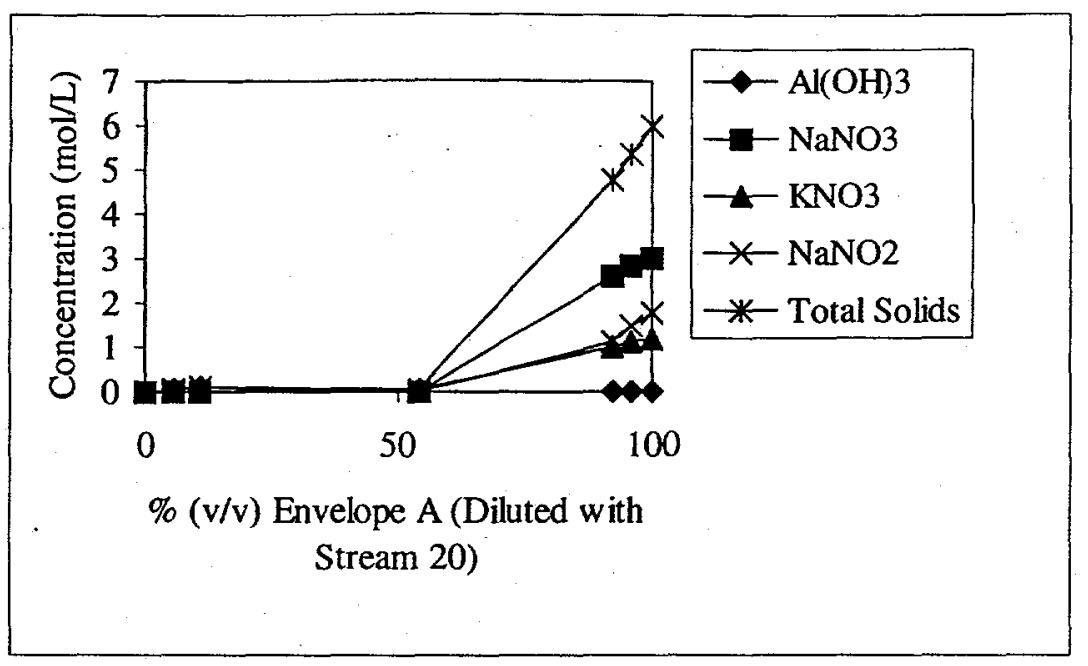

Figure 11. Effect of Mixing a Dilute Stream (Stream 20) with Envelope A on Solids Formation

In laboratory dilution experiments with actual waste from 241-AN-105 (Envelope A), dilution-induced gibbsite formation has not been observed (Herting 1997). Results for 241-AN-104 (Envelope A) were similar (Herting 1997). The free hydroxide concentration in these tanks was apparently high enough that aluminum precipitation did not occur within the range of dilutions evaluated. These laboratory results do not support or refute the results of the simulations. The simulations and laboratory results suggest that there is little or no gibbsite formed as a result of diluting Envelope A. This may be a result of the aluminum concentrations decreasing at a faster rate than $\mathrm{pH}$ levels (hydroxide concentration) and that the final $\mathrm{pH}$ is still sufficiently high to maintain aluminum in solution.

\section{CONCLUSIONS}

A series of chemical equilibrium calculations were conducted to evaluate the effect of mixing various waste streams on the formation of solids. The presence of solids in the waste stream can result in clogging filters, blinding exchange sites on resins, and increase the volume of nonradioactive solids sent to the High Level glassification plant. Data were not available to evaluate the effect of redox status on the formation of solids, although these are clearly very important processes. It was elected to addresses these issues in laboratory experiments and further modeling studies.

The simulated Envelope A (Tank AW-101) used throughout this study had a pH of 16.5 and a calculated ionic strength of 18. Approximately one third of the molar concentrations in the input aqueous phase was calculated to exist in the solid phase. Sodium, aluminum and potassium existed in Envelope A in molar concentrations and accounted for $>99.99 \%$ of the total cation concentration in the stream. Hydroxide, nitrate, nitrite, carbonate, and chloride accounted for $98.5 \%$ of the total molar anion 
concentration; hydroxide accounted for $45 \%$ and nitrate for $28 \%$ of the total molar anion concentration. Total organic carbon accounted for $<1 \%$ of the total molar anion concentration.

The simulated Envelope C (Tank AN-107) had a pH of 10.5 and an ionic strength of 19. The single greatest difference between Envelopes $A$ and $C$ is that the latter contained an order of magnitude more organic carbon. This organic carbon was assigned to approximately equal molar concentrations of formate and glycolate. These organic compounds were selected to represent TOC because they each account for the highest percentages of carbon in Envelope C. Additionally, Envelope C contains appreciably concentrations of complexants, including glycolate, HEDTA and EDTA. The EDTA was included in the simulated Envelope $\mathrm{C}$ to account for the presence of these compounds.

Envelope A solutions containing oxalate formed more solids than solutions containing only acetate, formate, or glycolate. The concentration of solids was sensitive to the concentration of these organic compounds. Envelope A was saturated with respect to sodium-oxalate. The other organic compounds were not evaluated as to whether they were saturated with respect to their respective sodium-salts. Very few of the organic compounds in Envelope A were calculated to exist as solids (unless the organics' concentrations were increased or some perturbation of the chemical system occurred).

Envelope A was very well buffered between $\mathrm{pH} 16.2$ and 14.6 , requiring $4.6 \mathrm{~mol} / \mathrm{L}$ of $\mathrm{HNO}_{3}$ to decrease the $\mathrm{pH}$ these $1.6 \mathrm{pH}$ units. Increasing the $\mathrm{HNO}_{3}$ concentration by an additional $1.3 \mathrm{~mol} / \mathrm{L}$, decreased the $\mathrm{pH}$ another 11 units, from $\mathrm{pH} 14.6$ to 3.6. This high buffering capacity of the feed in the high $\mathrm{pH}$ range is a valuable attribute for maintaining stream solutes in solution. Increases in $\mathrm{HNO}_{3}$ additions resulted in increases in the formation of solids. As the $\mathrm{pH}$ decreased to 2.25 and the amount of solids formed increased by $30 \%$. Interestingly, as the $\mathrm{pH}$ dropped from 16.2 to 14.6 , the total solids formed increased by $8 \%$. The increase in total solids was primarily attributed to increases in the concentration of $\mathrm{Al}(\mathrm{OH})_{3}$ and $\mathrm{NaNO}_{3}$. As the amount of $\mathrm{HNO}_{3}$ added increased, the ionic strength of the solutions gradually decreased. This latter trend is consistent with the notion that as more solids are formed in the increasingly acidic suspensions, the less solutes remain in solution.

Mixing various amounts of a dilute acid stream, an off-gas condensate (Stream 91), with Envelope A caused the $\mathrm{pH}$ of the mixture to decrease from 16.2 to 11.5. Increased acidity did not result in additional solids formation because of concomitant decreases in ionic strength. In the more basic solutions, sodium salt precipitates dominated the solid phase, whereas in the more acidic solutions, $\mathrm{Al}(\mathrm{OH})_{3}, \mathrm{Fe}(\mathrm{OH})_{3}, \mathrm{SiO}_{2}$ and $\mathrm{NaF}$ precipitates were more common, albeit in low molar concentrations, $<0.22 \mathrm{~mol} / \mathrm{L}$.

Effects of mixing Envelopes $\mathrm{A}$ and $\mathrm{C}$ were not addressed satisfactorily in these simulations. Some key thermodynamic data were missing from the database and only a limited number of organic and inorganic solutes could be included in the simulations. Some of the thermodynamic constants are presently being included in the database by the staff of OLI systems, Inc. Given these caveats, the simulations provided some insight 
into the heel issue. Mixing. Envelope $\mathrm{C}$ into Envelope $\mathrm{A}$ did not cause the concentration of total solids to increase. The cause for this may be in part attributed to the fact that the solute concentrations in these envelopes were used as model input in the simulations, therefore the solubility of the various organic solids were only moderately exceeded during the simulations. Mixing Envelope $\mathrm{C}$ into Envelope A caused the $\mathrm{pH}$ to decrease and the ionic strength to increase. Although the $\mathrm{pH}$ of the solution dropped when Envelope $\mathrm{C}$ was mixed into Envelope A, the total solids that precipitated did not increase

These simulations provided important guidance for future laboratory mixing studies. The guidance includes the following:

- Heel Issue: Evaluate the effect of mixing Envelopes A and B with Envelope C on solids formation and technetium exchangeability. Although technetium speciation was not conducted in these simulations, these data indirectly suggest that the various anions, including organic compounds, in the feed streams should be systematically evaluated for their propensity to convert technetium into a nonexchangeable species. Nonexchangeable technetium should be chemically speciated using operationally defined procedures and spectroscopic techniques to provide information necessary for correcting poor recovery by exchange resins. This is relevant to Items 1 and 9 of the Test Specifications for this task (Johnson 1999).

- Dilution Issue: Evaluate the effect of diluting Envelopes A, B, and C on the formation of solids and its impact on filtration and ion exchange. This is relevant to Item 2 and 7 of the Test Specifications for this task (Johnson 1999).

- Acidity Issue: Evaluate the effect of acidifying Envelopes A, B, and C on the formation of solids, and cesium and technetium ion exchange. Confirm that Envelope $\mathrm{A}$ has a high buffering capacity at elevated $\mathrm{pH}$ values $(\mathrm{pH} \sim 15)$. Identify the solid phases formed at various $\mathrm{pH}$ levels and determine the critical $\mathrm{pH}$ at which the various solids form. Identification of the solid phases is important for providing supporting evidence of modeling results. This is relevant to Items $3-6$ and 8 of the Test Specifications for this task (Johnson 1999).

- (Co)precipitation of radionuclides: Conduct experiments whereby solids identified in earlier experiments are purposely precipitated from simulated waste streams and evaluate whether radionuclides precipitate or coprecipitate with the solids. This is relevant to Items 1-8 of the Test Specifications for this task (Johnson 1999).

- Redox: Evaluate the extent that reducing conditions may exist in various streams by mixing various organics into Envelopes $\mathrm{A}, \mathrm{B}$, and $\mathrm{C}$ or combining Envelopes $A$ and $B$ with Envelope $C$ and measuring the redox status. If reducing conditions exist, the effect of reducing conditions on chromium, uranium, technetium, plutonium, nitrogen, iron, and manganese chemistry (specifically, the tendency of these elements to form solids and affect on ion exchange) will have to be evaluated. This is relevant to Items 1 and 9 of the Test Specifications for this task (Johnson 1999). 
- Additional Simulations: Re-run simulations after BNFL validate flowsheet compositions for various recycle streams (e.g., streams 20 and 91). BNFL is currently planning to incorporate $3 \mathrm{M} \mathrm{NaOH}$ leaching of HLW solids in flowsheet. This caustic leachate process will greatly alter the composition of stream 20 (the permeate from the HLW feed dewatering that feeds into the LAW treatment).

The data generated from these studies will provide important conceptual constructs (e.g., which solid-phase precipitates to include in model or whether to invoke redox chemistry, Tc-organic complexation, or radionuclide precipitation/coprecipitation) and numerical constants (e.g., solubility values) for more in-depth and technically defensible modeling of the various mixing scenarios. 


\section{APPROVALS}

Design Check

M.C. Thomptor_ 10/6/99

Chemical and Hydrogen Technology

Authors

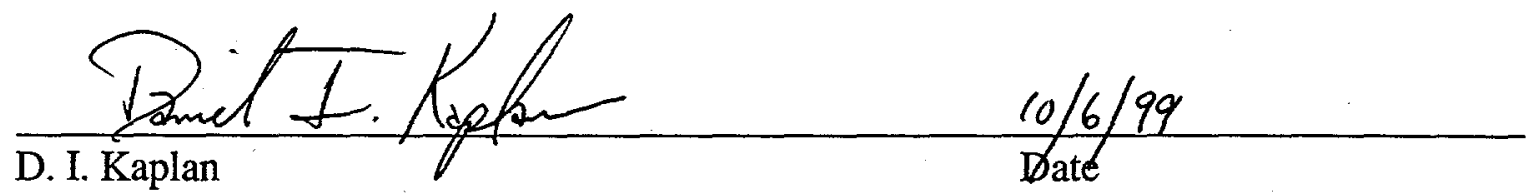

Waste Processing Technology

D. J. McCabe

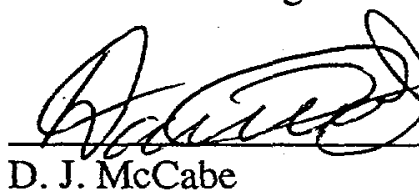

Waste Processing Technology

$\frac{\text { Domel I. Kiptor for Steven M. Ekxiz } 10 / 6 / 99}{\text { S. M. Serkiz }}$

Waste Processing Technology

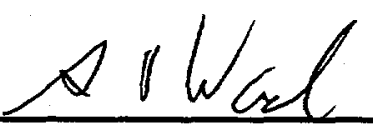

$10 / 6 / 99$

S. T. Wach, Manager

Waste Processing Technology 


\section{REFERENCES}

1. Barney, G. S., 1976, Vapor-Liquid-Solid Phase Equilibria of Radioactive Sodium Salt Wastes at Hanford, ARH-ST-133, Atlantic Richfield Hanford Company, Richland, Washington.

2. Barney, G. S., 1994, The Solubilities of Significant Organic Compounds in HLW Tank Supernate Solutions, WHC-SA-2565-FP, Westinghouse Hanford Company, Richland, Washington.

3. Barney, G. S., 1995, The Solubilities of Significant Organic Compounds in HLW Tank Supernate Solutions-FY 1995 Progress Report, WHC-EP-0899, Westinghouse Hanford Company, Richland, Washington.

4. Barney, G. S., 1996, Solubilities of Significant Organic Compounds in HLW Tank Supernate Solutions-FY 1996 Progress Report, WHC-EP-0899-2, B\&W Hanford Company, Richland, Washington.

5. Barney, G. S., 1997, Solubilities of Significant Organic Compounds in HLW Tank Supernate Solutions-FY 1997 Progress Report, HWC-EP-0899-2, B\&W Hanford Company, Richland, Washington.

6. Colebrook, K. C., Coleman, M. J., 1998a, TWRS Mass, Activity, and Heat Balance Assumptions Document, K0104_REP_015_PRC, Preliminary 5, 25 May 1998.

7. Colebrook, K. C., Coleman, M. J., 1998b, LAW/HLW Envelope A/D Mass \& Activity Balance (30 MT/d LAW Glass), K0104_REP_085_PRC, Preliminary 1, 31 January 1998.

8. Eibling, R., 1998, Envelope A Simulant, Presented at the WSRC Technical Meeting for the BNFL Hanford Waste Project, 10 December 1998.

9. Ruth A. Esch, 1996a,Tank Remediation System (TWRS) Privatization Private Contractor Samples Waste Envelope A Material Tank 241-AW-101 Summary Analytical Report, WHC-SD-WM-DP-204 REV. 0, November 20. 1996.

10. Ruth A. Esch, 1996b, Tank Remediation System (TWRS) Privatization Private Contractor Samples Waste Envelope B Material Tank 241-AN-105 Preliminary Analytical Report, November 20. 1996.

11. Ferrara, D. M., Crawford, C. L., Ha, B. C., Bibler, N. E., Choi, A. S., 1998, Vitrification of Four Radioactive Hanford Waste Samples, SRTC-BNFL-023. Rev. 2, Westinghouse Savannah River Company, Aiken, SC, January 5, 1998.

12. Herting, D. L., Welsh, T., Reynolds, D. A., 1986, Gibbsite Equilibrium in Simulated Liquid Waste, SD-WM-TI-211, Rockwell Hanford Operations, Richland Washington.

13. Johnson, M. E., 1997, TWRS Privatization Contract No. DE-AC06-96RL13308 LAW Feed Compositions for Dose Rate Assessments, K0104_COR-355_CLI, BNFL Inc, Richland, Washington.

14. Johnson, M. E., 1998, Approval of Envelope C Simulant Formulation for Sr/TRU Precipitation Tests, Ref. No. 000547, November 6, 1998.

15. Johnson, M. E., 1999, Mixing of Process Heels, Process Solutions, and Recycle Streams: Small-Scale Radioactive Mixing Test Specification, Rev. 0, Ref. No. 001579, January 29, 1999. 
16. Nash, C. A., Hanford Envelope A Characterization of Solids and Liquids, K0104_COR_341_CLI, Westinghouse Savannah River Company, Aiken, South Carolina, April 21, 1997.

17. OLI Software Systems, 1996, OLI Software Manual, New Jersey.

18. Orme, R. M., 1998, Waste Feed Delivery Technical Basis, Volume II, Waste Feed Delivery Flowsheet, HNF-1939, Vol. II, Rev. 0, 14 August 1998.

19. PNNL, 1998, Organic Analysis Progress Report FY1997, PNNL-11738, Pacific Northwest National Laboratory, Richland, Washington.

20. Reynolds, D. A., Herting, D. L, 1984, Solubilities of Sodium, Nitrate, Sodium Nitrite, and Sodium Aluminate in Simulated Nuclear Waste, RHO-RE-ST-14P, Rockwell International, Richland, WA, September 1984.

21. RFSH, 1997, TWRS Privatization Contractor Samples Low Activity Waste Envelope C Tank 241-AN-107, HNF-SD-WM-DP-205, Revision 1, Rust Federal Services of Hanford, Inc., Richland, Washington.

22. Sterner, S. M., Felmy, A. R., Melethil, P. K., Mason, M. J., Rustad, J. R., 1996, Extension of the ESP Model to High Base and High Aluminate Concentration, Letter Report, May 31, 1996, Pacific Northwest National Laboratory, Richland, Washington.

23. WSRC, 1998a, Tank Technical and Quality Assurance Plan for Sr/TRU Precipitation of Hanford High Level Waste, BNF-003-98-0012, Revision 0, Westinghouse Savannah River Company, Aiken, South Carolina.

24. WSRC, 1998b, Envelope C Simulant Formulation for Sr/TRU Precipitation Tests, TWRS-P Contract No. DE-AC06-96RL13308-W375, Westinghouse Savannah River Company, Aiken, South Carolina.

\section{APPENDICES}

Appendix A: Flowsheet Presented by Colebrook and Coleman (1998a).

Appendix B: Detailed OLI Results from the Mixing of Envelopes A and C.

Appendix C: Detailed OLI Results from the Mixing of Envelope A and Stream 20

Appendix D: Detailed OLI Results from the Mixing of Envelope A and Stream 91 (OffGas Condensate) 


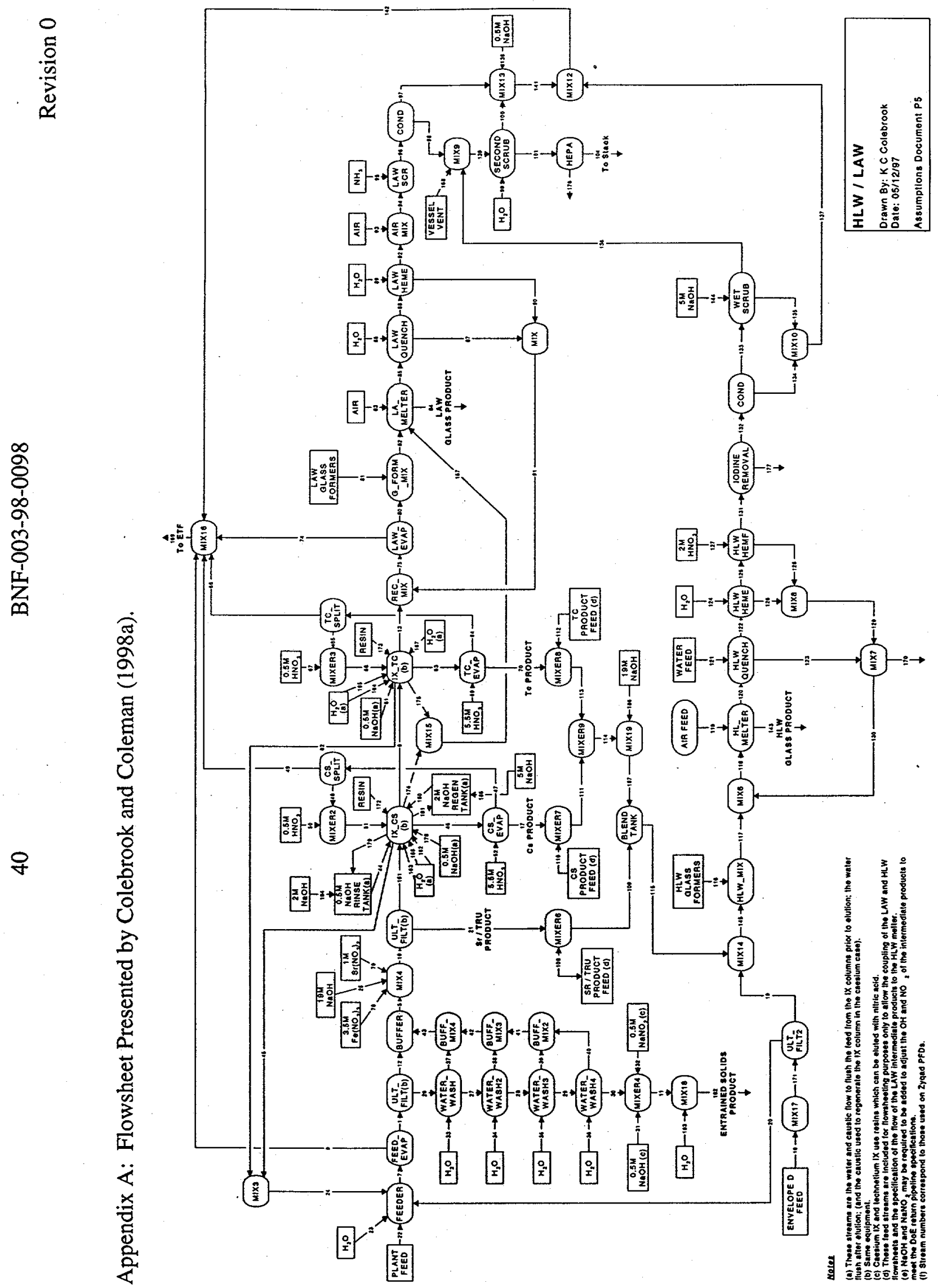




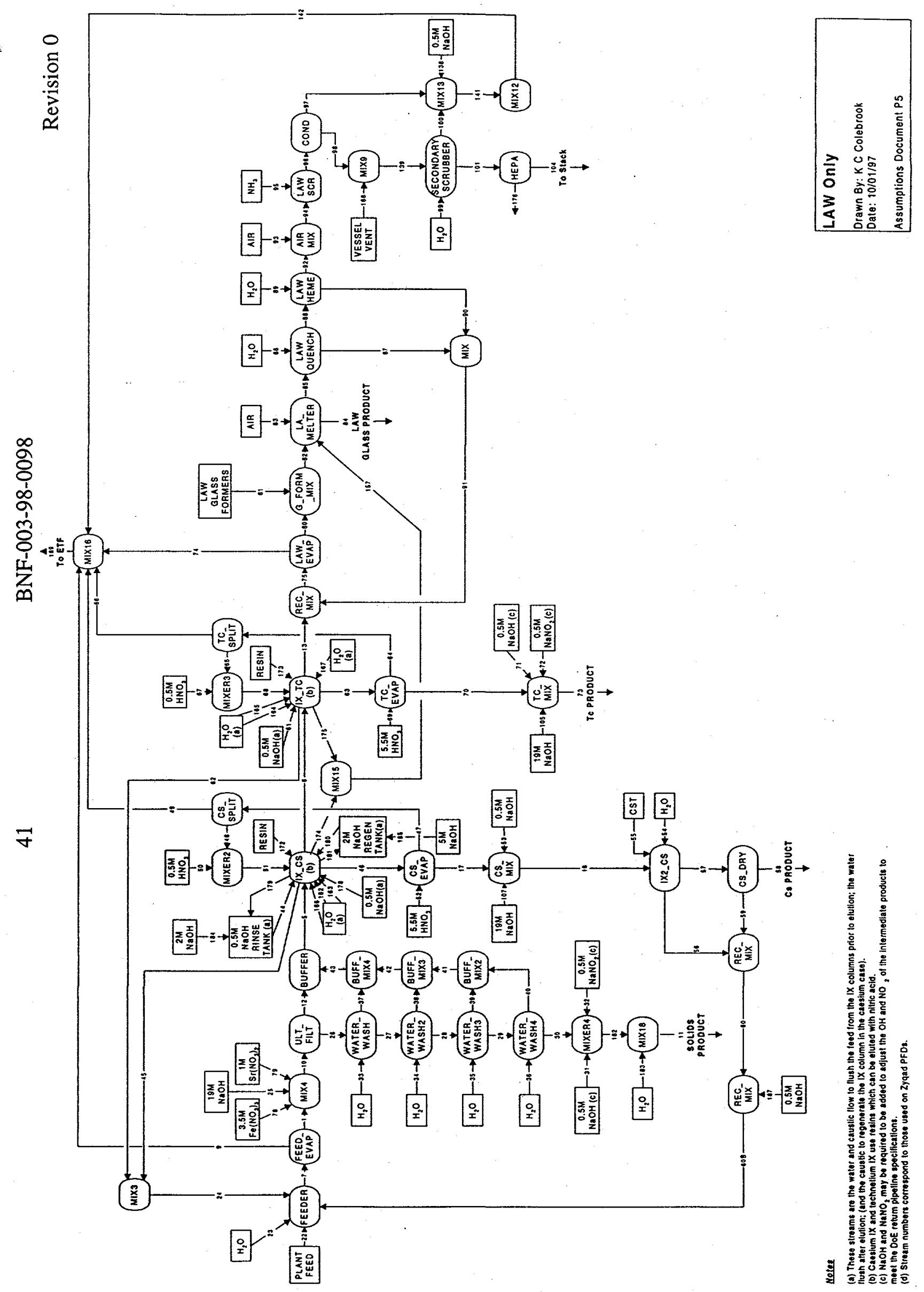


Appendix B: Detailed OLI Results from the Mixing of Envelopes A and C

\begin{tabular}{|c|c|c|c|c|c|c|c|c|c|}
\hline & & \multicolumn{8}{|c|}{ Env A:Env C (mol:mol) } \\
\hline & & $1: 0$ & $20: 1$ & $14: 1$ & $11: 1$ & $5: 1$ & $2: 1$ & $1: 1$ & $0: 1$ \\
\hline$\%$ Env A & $\mathrm{mol} / \mathrm{mol}$ & 100 & 95 & 93 & 92 & 83 & 67 & 50 & 0 \\
\hline Tot vol. Env A & $\mathrm{m}^{3} / \mathrm{hr}$ & NA & $9.77 \mathrm{E}+00$ & 3.01E-04 & 2.37E-04 & $1.08 \mathrm{E}-04$ & $4.30 \mathrm{E}-05$ & $2.15 \mathrm{E}-05$ & NA \\
\hline Tot vol. Env C & $\mathrm{m}^{3} / \mathrm{hr}$ & 0 & $2.52 \mathrm{E}-05$ & $2.52 \mathrm{E}-05$ & $2.52 \mathrm{E}-05$ & $2.52 \mathrm{E}-05$ & $2.52 \mathrm{E}-05$ & $2.52 \mathrm{E}-05$ & 0 \\
\hline \% Env A & vol/vol & 100 & 100 & 92 & 90 & 81 & 63 & 46 & 0 \\
\hline $\mathrm{pH}^{\circ}$ & unitless & 16.2 & 16.1 & 16.1 & 16.1 & 16.0 & 15.9 & 15.7 & 10.4 \\
\hline Total Aq. & $\mathrm{mol} / \mathrm{hr}$ & 11.46 & 21.91 & 15.66 & 12.53 & 6.29 & 3.17 & 2.14 & 1.07 \\
\hline Total Solids & $\mathrm{mol} / \mathrm{hr}$ & 1.42 & 2.73 & 1.95 & 1.57 & 0.79 & 0.40 & 0.26 & 0.16 \\
\hline Volume $\mathrm{Aq}$ & $\mathrm{m}^{3} / \mathrm{hr}$ & $1.83 \mathrm{E}-04$ & $3.52 \mathrm{E}-04$ & $2.52 \mathrm{E}-04$ & $2.02 \mathrm{E}-04$ & $1.03 \mathrm{E}-04$ & $5.32 \mathrm{E}-05$ & $3.68 \mathrm{E}-05$ & $1.93 \mathrm{E}-05$ \\
\hline Volume Solids & $\mathrm{m}^{3} / \mathrm{hr}$ & $5.37 \mathrm{E}-05$ & $1.03 \mathrm{E}-04$ & $7.37 \mathrm{E}-05$ & $5.90 \mathrm{E}-05$ & $2.97 \mathrm{E}-05$ & $1.49 \mathrm{E}-05$ & $9.90 \mathrm{E}-06$ & $5.82 \mathrm{E}-06$ \\
\hline Ionic Strength & unitless & 17.50 & 17.52 & 17.53 & 17.55 & 17.67 & 18.22 & 18.98 & 19.05 \\
\hline $\mathrm{NaF}$ & $\mathrm{mol} / \mathrm{L}$ & 0.027 & 0.017 & 0.013 & 0.009 & 0 & 0 & 0 & 0 \\
\hline $\mathrm{NaNO}_{3}$ & $\mathrm{~mol} / \mathrm{L}$ & 3.009 & 3.147 & 3.201 & 3.248 & 3.479 & 3.923 & 4.350 & 4.858 \\
\hline $\mathrm{Ca}(\mathrm{OH})_{2}$ & $\mathrm{~mol} / \mathrm{L}$ & 0.002 & 0.002 & 0.003 & 0.003 & 0.004 & 0.003 & 0 & 0 \\
\hline $\mathrm{KNO}_{3}$ & $\mathrm{~mol} / \mathrm{L}$ & 1.173 & 1.089 & 1.056 & 1.027 & 0.881 & 0.597 & 0.326 & 0 \\
\hline $\mathrm{Na}_{3} \mathrm{FSO}_{4}$ & $\mathrm{~mol} / \mathrm{L}$ & 0.008 & 0.015 & 0.018 & 0.020 & 0.030 & 0.026 & 0.019 & 0 \\
\hline $\mathrm{NaNO}_{2}$ & $\mathrm{~mol} / \mathrm{L}$ & 1.792 & 1.656 & 1.600 & 1.551 & 1.298 & 0.756 & 0.181 & 0 \\
\hline $\mathrm{CaCO}_{3}$ & $\mathrm{~mol} / \mathrm{L}$ & 0 & 0 & 0 & 0 & 0 & 0 & 0.001 & 0.009 \\
\hline $\mathrm{Fe}(\mathrm{OH})_{3}$ & $\mathrm{~mol} / \mathrm{L}$ & 0 & 0 & 0 & 0 & 0 & 0 & 0.002 & 0.049 \\
\hline $\mathrm{NaCOOH}$ & $\mathrm{mol} / \mathrm{L}$ & 0 & 0.073 & 0.105 & 0.133 & 0.267 & 0.522 & 0.759 & 1.192 \\
\hline $\mathrm{NaHCO}_{3}$ & $\mathrm{~mol} / \mathrm{L}$ & 0 & 0 & 0 & 0 & 0 & 0 & 0 & 0.068 \\
\hline $\mathrm{NaAlCO}_{3}(\mathrm{OH})_{2}$ & $\mathrm{~mol} / \mathrm{L}$ & 0 & 0 & 0 & 0 & 0 & 0 & 0 & 0.023 \\
\hline Total Solids & $\mathrm{mol} / \mathrm{L}$ & 6.011 & 5.999 & 5.995 & 5.991 & 5.958 & 5.827 & 5.638 & 6.203 \\
\hline
\end{tabular}


Appendix C: Detailed OLI Results from the Mixing of Envelope A and Stream 20 (Permeate from HLW Feed Dewatering to LAW Treatment)

\begin{tabular}{|c|c|c|c|c|c|c|c|c|}
\hline & & \multicolumn{7}{|c|}{ Stream20:Env A (mol:mol) } \\
\hline & & $1: 0$ & $20: 1$ & $10: 1$ & $1: 1$ & $1: 10$ & $1: 20$ & $0: 1$ \\
\hline$\%$ Env A & $\mathrm{mol} / \mathrm{mol}$ & 0 & 5 & 9 & 50 & 91 & 95 & 100 \\
\hline Tot Vol Env A & $\mathrm{m}^{3} / \mathrm{hr}$ & 0 & $2.151 \mathrm{E}-05$ & $2.151 \mathrm{E}-05$ & $2.1514 \mathrm{E}-05$ & $2.1513 \mathrm{E}-4$ & $4.3028 \mathrm{E}-4$ & $3.612 E-4$ \\
\hline Tot. Vol St. 20 & $\mathrm{~m}^{3} / \mathrm{hr}$ & $3.612 \mathrm{E}-4$ & $3.612 \mathrm{E}-4$ & $1.806 \mathrm{E}-4$ & $1.806 \mathrm{E}-05$ & $1.806 \mathrm{E}-05$ & $1.806 \mathrm{E}-05$ & 0 \\
\hline$\%$ Env A & $\mathrm{vol} / \mathrm{vol}$ & 0 & 6 & 10 & 54 & 92 & 96 & 100 \\
\hline $\mathrm{pH}$ & unitless & 12.56 & 13.43 & 13.74 & 15.24 & 16.04 & 16.10 & 16.18 \\
\hline Total Aq. & $\mathrm{mol} / \mathrm{hr}$ & 20.029 & 21.338 & 11.322 & 2.2971 & 11.799 & 22.208 & 11.464 \\
\hline Total Solids & $\mathrm{mol} / \mathrm{hr}$ & $3.475 \mathrm{E}-05$ & 0.021373 & 0.020704 & 0.0032916 & 1.1061 & 2.4057 & 1.4224 \\
\hline Volume Aq. & $\mathrm{m} 3 / \mathrm{hr}$ & $3.61 \mathrm{E}-04$ & $3.79 \mathrm{E}-04$ & $1.99 \mathrm{E}-04$ & $3.86 \mathrm{E}-05$ & $1.90 \mathrm{E}-04$ & $3.56 \mathrm{E}-04$ & $1.83 \mathrm{E}-04$ \\
\hline Volume Solids & $\mathrm{m} 3 / \mathrm{hr}$ & $1.15 \mathrm{E}-11$ & $6.84 \mathrm{E}-07$ & $6.62 \mathrm{E}-07$ & $1.47 \mathrm{E}-07$ & $4.24 \mathrm{E}-05$ & $9.14 \mathrm{E}-05$ & 005373 \\
\hline Ionic Strength & unitless & 0.08 & 1.00 & 1.86 & 11.26 & 16.60 & 16.99 & 17.50 \\
\hline $\mathrm{Al}(\mathrm{OH})_{3}$ & $\mathrm{~mol} / \mathrm{L}$ & 0 & $5.62 \mathrm{E}-02$ & $1.04 \mathrm{E}-01$ & $1.60 \mathrm{E}-02$ & 0 & 0 & 0 \\
\hline $\mathrm{NaF}$ & $\mathrm{mol} / \mathrm{L}$ & 0 & 0 & 0 & 0 & $2.20 \mathrm{E}-02$ & $2.43 \mathrm{E}-02$ & $2.68 \mathrm{E}-02$ \\
\hline $\mathrm{NaNO}_{3}$ & $\mathrm{~mol} / \mathrm{L}$ & 0 & 0 & 0 & 0 & $2.60 \mathrm{E}+00$ & $2.80 \mathrm{E}+00$ & $3.01 \mathrm{E}+00$ \\
\hline $\mathrm{Ca}(\mathrm{OH})_{2}$ & $\mathrm{~mol} / \mathrm{L}$ & 0 & 0 & 0 & $9.27 \mathrm{E}-04$ & $1.55 \mathrm{E}-03$ & $1.61 \mathrm{E}-03$ & $1.67 \mathrm{E}-03$ \\
\hline $\mathrm{KNO}_{3}$ & $\mathrm{~mol} / \mathrm{L}$ & 0 & 0 & 00 & $6.80 \mathrm{E}-02$ & $1.02 \mathrm{E}+00$ & $1.10 \mathrm{E}+00$ & $1.17 \mathrm{E}+00$ \\
\hline $\mathrm{Na}_{3} \mathrm{FSO}_{4}$ & $\mathrm{~mol} / \mathrm{L}$ & 0 & 0 & 0 & 0 & $6.49 \mathrm{E}-03$ & $7.37 \mathrm{E}-03$ & $8.17 \mathrm{E}-03$ \\
\hline $\mathrm{NaNO}_{2}$ & $\mathrm{~mol} / \mathrm{L}$ & 0 & 0 & 0 & 0 & $1.11 E+00$ & $1.45 \mathrm{E}+00$ & $1.79 \mathrm{E}+00$ \\
\hline $\mathrm{Cd}\left(\mathrm{NO}_{2}\right)_{2}$ & $\mathrm{~mol} / \mathrm{L}$ & $1.04 \mathrm{E}-06$ & 0 & 0 & 0 & 0 & 0 & 0 \\
\hline $\mathrm{UO}_{2}(\mathrm{OH})_{2}$ & $\mathrm{~mol} / \mathrm{L}$ & $9.52 \mathrm{E}-05$ & 0 & 0 & 0 & 0 & 0 & 0 \\
\hline $\mathrm{Ca}_{3}\left(\mathrm{PO}_{4}\right)_{2}$ & $\mathrm{~mol} / \mathrm{L}$ & 0 & $2.28 \mathrm{E}-05$ & $4.89 \mathrm{E}-05$ & 0 & 0 & 0 & 0 \\
\hline Total Solids & $\mathrm{mol} / \mathrm{L}$ & $9.62 \mathrm{E}-05$ & $5.63 \mathrm{E}-02$ & $1.04 \mathrm{E}-01$ & $8.49 \mathrm{E}-02$ & $4.76 \mathrm{E}+00$ & $5.38 \mathrm{E}+00$ & $6.01 E+00$ \\
\hline
\end{tabular}


Appendix D: Detailed OLI Results from the Mixing of Envelope A and Stream 91 (Off-Gas Condensate)

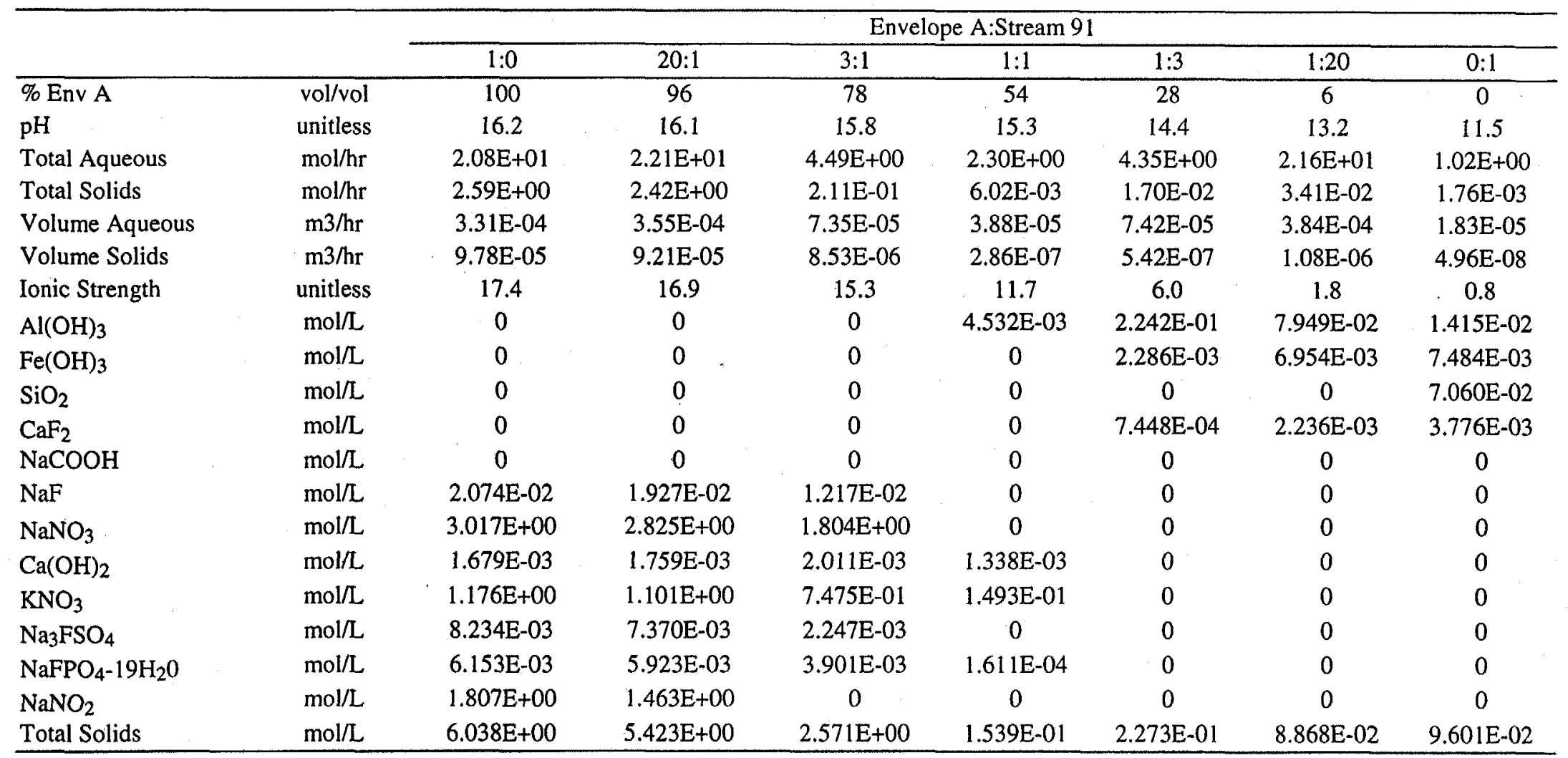




\section{DISTRIBUTION:}

M. E. Johnson, BNFL, Inc.

B. T. Butcher, 737-A

A. S. Choi, 704-1T

N. M. Hassan, 773-A

D. I. Kaplan, 773-43A

D. J. McCabe, 773-42A

S. M. Serkiz, 773-A

W. E. Stevens, 737-A

H. F. Sturm, 773-A

M. C. Thompson, 773-A

S. T. Wach, 773-42A

BNFL Part B Document File, B. Skwarek, 773-41A 